\title{
Designing Scaffolds for Corneal Regeneration
}

\author{
Mark Ahearne,* Julia Fernández-Pérez, Sophia Masterton, Peter W. Madden, \\ and Promita Bhattacharjee
}

\begin{abstract}
Corneal blindness is one of the most common causes of vision loss worldwide, affecting millions of people. To treat these patients, researchers have been examining different approaches to engineer corneal scaffolds suitable for transplantation. Scaffolds have been developed to replace part or all of the cornea depending on the patient requirements. Both acellular and cell-seeded scaffolds have been tested in animal models. Materials that have been under investigation for manufacturing scaffolds include collagen, silk fibroin, amniotic membrane, decellularized cornea, fibrin, chitosan, gelatin, agarose, alginate, and hyaluronic acid in addition to several synthetic polymers. Different combinations of materials, fiber crosslinking techniques, and incorporation of bioactive molecules have also been examined. Factors such as the physical properties, cytocompatibility, degradation behavior, and optical characteristics have to be considered when selecting a suitable scaffold material. Recent advancements in materials fabrication techniques such as bioprinting, electrospinning, and different collagen alignment techniques, allow scaffolds to be generated that more accurately mimic the structure of the corneal stroma. A number of scaffolds have commenced clinical trials to determine their suitability for corneal regeneration.
\end{abstract}

\section{Introduction}

The cornea is a transparent, multilayered component of the ocular surface whose primary function is to focus light onto the lens where it is directed toward the retina. Each distinct layer of the cornea differs in composition, structure, function, and the

Prof. M. Ahearne, J. Fernández-Pérez, S. Masterton, Dr. P. W. Madden, Dr. P. Bhattacharjee

Trinity Centre for Biomedical Engineering

Trinity Biomedical Sciences Institute

Trinity College Dublin

The University of Dublin

Dublin 2, Ireland

E-mail: ahearnm@tcd.ie

Prof. M. Ahearne, J. Fernández-Pérez, S. Masterton,

Dr. P. W. Madden, Dr. P. Bhattacharjee

Department of Mechanical and Manufacturing Engineering

School of Engineering

Trinity College Dublin

The University of Dublin

Dublin 2, Ireland

The ORCID identification number(s) for the author(s) of this article can be found under https://doi.org/10.1002/adfm.201908996.

(C) 2020 The Authors. Published by WILEY-VCH Verlag GmbH \& Co. KGaA, Weinheim. This is an open access article under the terms of the Creative Commons Attribution License, which permits use, distribution and reproduction in any medium, provided the original work is properly cited.

DOI: 10.1002/adfm.201908996 type of cells resident (Figure 1). The epithelium is the outer layer of the cornea and consists of stratified epithelial cells that are replenished from stem cells located in limbal crypts along the corneal-conjunctival boundary. ${ }^{[1]}$ These cells form a barrier that allows the diffusion of oxygen and essential nutrients from the tear film but prevents pathogens and debris penetrating into the eye. The Bowman's layer along with a basement membrane are acellular collagenous layers that separate the epithelium from the stroma. The Bowman's layer has a high stiffness ${ }^{[2]}$ but poor regenerative properties after injury. The stroma, which constitutes $90 \%$ of the total corneal thickness, comprises a highly structured orthogonal arrangement of small, evenly spaced collagen fibrils, 31-34 $\mathrm{nm}$ in diameter ${ }^{[3]}$ and surrounded by other collagens and proteoglycans. The stroma contains neural crest derived cells called keratocytes that maintain the tissue's homeostasis and can be activated upon injury. The Descemet's membrane connects the endothelium to the posterior side of the stroma. The inner layer of the cornea is the endothelium and consists of a single layer of endothelial cells whose primary function is regulating the hydration of the whole cornea. Damage to this layer results in swelling and impairment of vision. The overall thickness of the cornea is $\approx 0.53 \mathrm{~mm}$ at the center, increasing to $0.71 \mathrm{~mm}$ closer to the edge..$^{[4]}$

Damage to the cornea's cells or extracellular matrix (ECM) resulting from medical conditions or physical damage can lead to impaired vision. For many indications, a corneal transplant is required to preserve or improve the patient's sight. Corneal transplants have a high success rate relative to other tissues and organs partially due to the absence of vascular and lymphatic vessels in the cornea reducing the chances of immune rejection. ${ }^{[5]}$ However, globally there is a shortage of donor corneas suitable for transplantation for a variety of reasons including lack of awareness about donations, lack of facilities in some countries to remove and store corneas and not all corneas being suitable for donation. ${ }^{[6]}$ For these reasons there has been considerable interest in the need to develop alternative treatment strategies.

One alternative to transplanting corneas is to use a keratoprosthesis. These devices replace the cornea with a transparent polymer and enable the full or partial restoration of vision. The most commonly used keratoprosthesis is the Boston keratoprosthesis, although, despite its success in improving vision for many patients, several complications are associated with these implants including an increased risk of glaucoma, ${ }^{[7]}$ endophthalmitis, ${ }^{[8]}$ 
retroprosthetic membrane formation, ${ }^{[9]}$ and corneal melt. ${ }^{[10]}$ Other keratoprosthesis include the AlphaCor and the osteo-odonto keratoprosthesis, although these too have many limitations. Currently, keratoprostheses are normally only used in cases where the patient is unable to sustain a corneal transplant and this is the only option to regain some vision.

Tissue engineering approaches offer a different solution to the lack of donor corneas available for transplantation. Most engineered tissues are fabricated using a top-down approach by combining cells with a biomaterial-based scaffold to replicate the real tissue. Unlike keratoprostheses that contain no cells, in principle, tissue engineered corneas can adapt to biological and biophysical cues in a similar manner to native corneas. Tissue engineering is still relatively new, the concept was first investigated in the early 1990 's ${ }^{[11]}$ hence there is considerable research still continuing into its development and application. Two key factors in determining the potential of an engineered tissue to accurately mimic native tissue is the type of material used to fabricate the scaffold and how the scaffold is manufactured. A number of recent review papers and book chapters have focused on different types of scaffolds for corneal tissue engineering including stromal scaffolds, ${ }^{[12]}$ nanomaterial scaffolds, ${ }^{[13]}$ decellularized scaffolds, ${ }^{[14]}$ and bioprinted scaffolds. ${ }^{[15]}$ Here, we provide a more comprehensive overview of corneal scaffolds to repair or replace the different layers of the cornea. In addition, a systematic process for designing corneal scaffolds has been outlined. Several important factors that need to be considered before designing corneal scaffolds are discussed, different biomaterials that can be used to generate scaffolds suitable for engineering cornea are evaluated and several advanced fabrication techniques and novel scaffold designs are considered. Finally, a future perspective is provided discussing where corneal tissue engineering might be heading.

\section{Design Considerations}

It is often beneficial to outline a clear design process prior to the commencement of any design project. An example of how such a process could be applied to designing corneal scaffolds is shown in Table 1. First, it is important to ask what is the problem that we are trying to solve and whether a scaffold is necessary. For cornea, the problem is a lack of healthy donor tissue to replace part or all of a damaged or diseased cornea. While scaffold free approaches to this problem have some merit, scaffolds provide a useful artificial matrix to allow a tissue to form. Once the problem is understood, a thorough review of literature and patents should commence to determine the progress made in addressing this problem, the limitations with other approaches and potentially identify new solutions. Next, the specific user and material requirements of the scaffolds need to be defined. Using this information, a prototype should be designed, fabricated, and assessed physically and biochemically. These steps should be repeated until a scaffold that fulfills all the user requirements has been developed. Finally, it is important to consider the regulatory approval process early in the design process. It may be advantageous to use materials and fabrication processes that have already undergone approval for other applications.

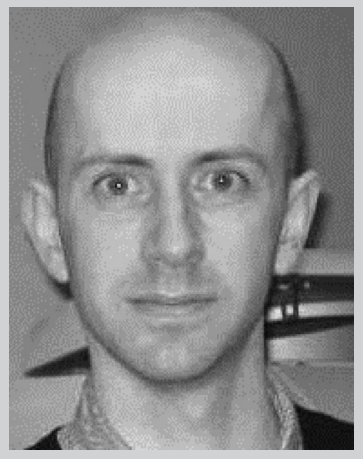

Mark Ahearne is Assistant Professor in Biomedical Engineering at Trinity College Dublin, The University of Dublin. He received a B.E. in Mechanical Engineering from the University of Limerick in 2001, an M.Sc. in Cell and Tissue Engineering from Keele University in 2003, and a Ph.D. in Biomedical Engineering from Keele University in 2007. He subsequently worked as a research fellow at Keele University and Trinity College Dublin before being appointed to his current position in 2015. His research interests include corneal regeneration, tissue engineering, biomaterials, and ocular mechanobiology.

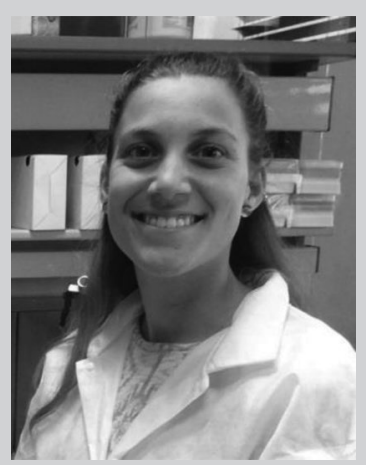

Julia Fernández-Pérez is a Ph.D. student at the Trinity Center for Biomedical Engineering at Trinity College Dublin. She received a B.Sc. in Human Biology from Pompeu Fabra University in Barcelona. She graduated from the Technical University of Dresden, where she obtained her M.Sc. in Molecular Bioengineering. She is currently developing alternatives to traditional corneal transplantation using tissue engineering approaches, focusing on the use of decellularized matrices.

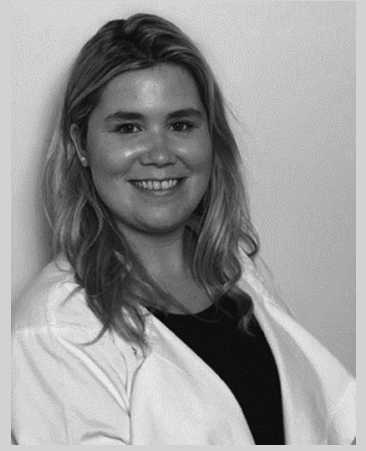

Sophia Masterton is a Ph.D. candidate at Trinity Centre for Biomedical Engineering focusing on corneal epithelium mechanobiology. She obtained her M.Sc. degree from Trinity College Dublin in 2014 in Molecular Medicine and her B.Sc. in Biochemistry from University College Dublin. Her research interests include the mechanical regulation of the corneal epithelium with a focus on how this affects stem cell maintenance. Her current work is examining shear stress regulation of corneal epithelial cells and deciphering the role of mechanical regulatory mechanisms in the corneal epithelium.

\subsection{Surgical Application}

One of the first factors to consider when designing a scaffold for corneal regeneration is how it will be applied. Depending on the type of injury or medical condition that a patient 
(A)

(C)

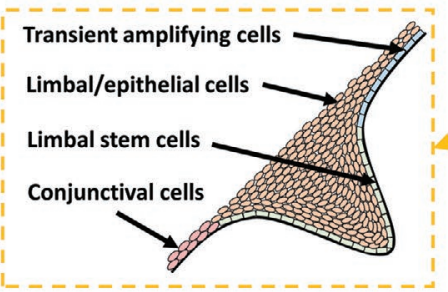

(B)

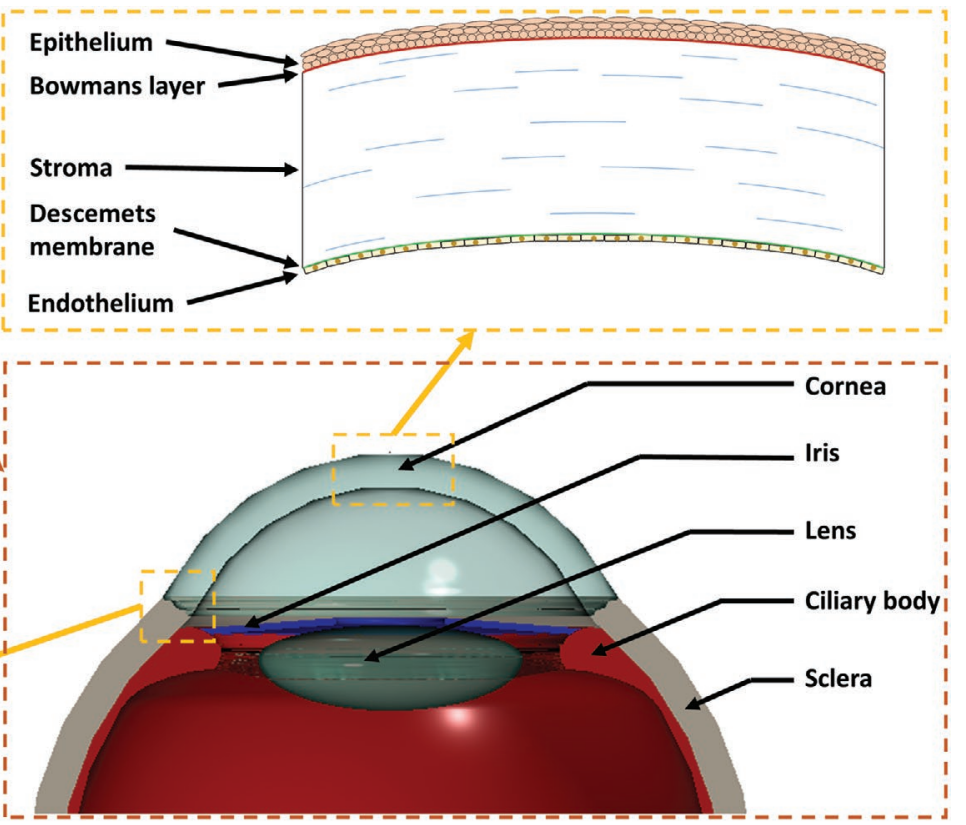

Figure 1. Schematic representations of A) the human eye with the cornea visible on the anterior surface; B) cross-section of part of the cornea showing the different layers present; C) cross-section of a limbal crypt with the different cell types; D) cross-section of the anterior segments of the eye.

suffered, several different types of surgeries or keratoplasties can be used to restore vision (Table 2). Traditionally, penetrating keratoplasty (PKP) involves the removal of the full thickness of the central cornea, leaving only a small rim of tissue near the limbal interface (Figure 2). A donated cornea is then positioned in the space left by the patient's cornea and sutured in place. While PKP is still relatively common, alternative procedures that require specific layers of the cornea to be transplanted such as anterior lamellar keratoplasty (ALK), deep anterior lamellar keratoplasty (DALK), Descemet's

Table 1. Design process for developing corneal scaffolds.

\begin{tabular}{|c|c|}
\hline Design process & Application to cornea \\
\hline Define problem & A lack of corneal tissue suitable for keratoplasties \\
\hline Research current solutions & Keratoprosthesis, stem cells, tissue engineering, etc. \\
\hline Define user requirement & $\begin{array}{c}\text { For patient: to restore and maintain vision without } \\
\text { pain or medical complications } \\
\text { For surgeon: easy to handle and suture } \\
\text { For industry: cost, market size, and scalability }\end{array}$ \\
\hline Specify material requirement & $\begin{array}{l}\text { Biocompatibility, cell adhesion, regulation of cell } \\
\text { behavior, degradation, mechanical properties, } \\
\text { transparency, etc. }\end{array}$ \\
\hline Design prototype & $\begin{array}{l}\text { Select suitable material, fabrication process, } \\
\text { sterilization technique, etc. }\end{array}$ \\
\hline Evaluate design & $\begin{array}{l}\text { In vitro using appropriate cells in culture, in vivo } \\
\text { using animal model; both physical and biological } \\
\text { properties need to be considered }\end{array}$ \\
\hline Optimization & $\begin{array}{l}\text { Use findings of previous steps to modify and } \\
\text { improve the scaffold design }\end{array}$ \\
\hline Seek regulatory approval & $\begin{array}{l}\text { Interact with regulatory bodies early to discuss } \\
\text { the feasibility of clinical translating design to treat } \\
\text { patients }\end{array}$ \\
\hline
\end{tabular}

membrane endothelial keratoplasty (DMEK), and Descemet's stripping endothelial keratoplasty (DSEK) have become increasingly popular. Between 2005 and 2014, the percentage of keratoplasties in United States that were PKP fell from $95 \%$ to $42 \%{ }^{[16]}$ with similar trends found in other countries. ${ }^{[17]}$ Transplantation of limbal tissue (LT) has also become more popular in recent years as a method of treating conditions that result in limbal stem cell deficiencies.

The type of surgery that is required has a significant influence on the type of scaffold required. For procedures such as LT or DMEK, a thin, flexible, and permeable film capable of supporting the cells is ideal. For DMEK, the film would also need to allow it to be rolled up to enable its insertion under the cornea and it should degrade without the release of any cytotoxic or inflammatory constituents. For surgeries involving replacement of the stroma, a thicker 3D scaffold capable of containing cells would be needed.

\subsection{Cells}

Once the type of keratoplasty is known, the next decision is to determine if it is necessary to culture cells in the scaffold prior to transplantation or to design the scaffold to allow the patient's own cells to repopulate it in vivo post-transplantation. In cases where there is a lack of endothelial cells, it will be necessary to culture cells on the scaffold prior to transplantation as corneal endothelial cells have poor proliferative capacity due to being arrested in the G1 phase of the cell cycle ${ }^{[18]}$ and just implanting a biomaterial without cells would likely be of little benefit. Similarly, for patients with limbal stem cell deficiencies, cells are required to repopulate the limbal region of the eye. Acellular biomaterials could be used to deliver specific biomolecules to accelerate regeneration and repair, with amniotic membranes 
Table 2. Types of corneal surgery and clinical indications.

\begin{tabular}{|c|c|c|c|}
\hline Surgery & Abbreviation & Layers needed & Possible indications \\
\hline Penetrating keratoplasty & PKP & Full thickness cornea & Severe keratoconus with damage to endothelium \\
\hline Anterior lamellar keratoplasty & ALK & Epithelium, Bowmans layer, partial stroma & Keratoconus, anterior scarring \\
\hline Deep anterior lamellar keratoplasty & DALK & Epithelium, Bowmans layer, most of the stroma & Keratoconus \\
\hline Descemets membrane endothelial keratoplasty & DMEK & Endothelium, Descemets membrane & Bullous keratopathy, Fuchs dystrophy \\
\hline Descemets stripping endothelial keratoplasty & DSEK & $\begin{array}{l}\text { Endothelium, Descemets membrane, partial } \\
\text { stroma }\end{array}$ & Bullous keratopathy, Fuchs dystrophy \\
\hline Limbal transplant & LT & Limbus & $\begin{array}{l}\text { Limbal stem cell deficiency, Stephen-Johnson syndrome, } \\
\text { aniridia }\end{array}$ \\
\hline
\end{tabular}

currently used in this way to deliver molecules capable of inhibiting inflammation, scarring, and angiogenesis. ${ }^{[19]}$

Different reports have investigated the use of cell seeded and acellular scaffolds to replace the stroma, although few studies have undertaken direct comparisons between the two. To promote cell infiltration of acellular scaffolds post-transplantation, the scaffolds need to be sufficiently porous to allow cells to enter ${ }^{[20]}$ or contain extracellular matrix proteins that the cells can degrade or remodel. ${ }^{[21]}$ Topographical cues such as aligned fibers may also be used to guide cells into a scaffold. ${ }^{[22]}$ Biochemical cues could also be incorporated into the scaffold to promote a chemotactic response and increase cell infiltration and proliferation. ${ }^{[23]}$ However, it should be noted that cells from rabbit and human corneas behave quite differently to each other ${ }^{[24]}$ and the size, thickness, and mechanical behavior of rabbit corneas also differs to human, ${ }^{[25]}$ therefore the rabbit data may not be directly translatable to humans.

Should it be decided that scaffolds are to be seeded with cells prior to transplantation, the source and phenotype of the cells has to be considered. The three main cell types in the cornea (epithelial, stromal, and endothelial) all have different challenges associated with their culture and application. Limbal derived epithelial cells can be contaminated by stromal cells quite easily and normally require a feeder layer to allow their expansion in culture. Stromal cells become fibroblastic in the presence of serum but are slow to proliferate in serum free conditions. One approach to overcome this limitation is to expand the cells in serum and then switch to a supplemented serum free medium that allows the partial restoration of the cell phenotype. ${ }^{[26]}$ Endothelial cells are particularly difficult to culture particularly as most donors as quite old and their cells no longer support proliferation.

While autologous cells may reduce the risk of rejection, these can be difficult to obtain from the patient's own cornea in sufficient quantities due to the probable lack of healthy tissue. Some studies have taken limbal cells from the patient's healthy eye, expanded these cells in vitro, and transferred them to the damaged eye using a scaffold. ${ }^{[27]}$ Cells can also be isolated from other tissues in the body or other sources and used to populate scaffolds for corneal stromal regeneration. Bone marrow derived mesenchymal stem cells (BMSCs), ${ }^{[28]}$ adipose derived stem cells (ASCs), ${ }^{[29]}$ and embryonic stem cells $(\mathrm{ESCs})^{[30]}$ and umbilical cord stem cells (USCs) ${ }^{[31]}$ have all been shown to be capable of differentiating toward a keratocyte lineage when cultured under specific biochemical conditions. However, a recent study by Dos Santos et al. showed that corneal derived stem cells were better at developing a keratocyte lineage and were less inflammatory compared to BMSCs, ASCs, and USCs. ${ }^{[32]}$ In addition, it has recently been suggested that MSCs are not truly stem cells when in the body but rather they just release molecules to support and regulate the existing cell populations after implantation. ${ }^{[33]}$ Induced pluripotent stem cells (iPSCs) have also been suggested as an alternative source of stem cells and have been shown to be capable of inducing epithelial, keratocyte, and endothelial phenotypes although challenges such as genetic variability and unwanted differentiation remain to be overcome. ${ }^{[34]}$

An alternative to using a scaffold is to culture cells over a prolonged period and allow the cells to generate new tissue using a "bottom-up approach" rather than a "top-down approach."
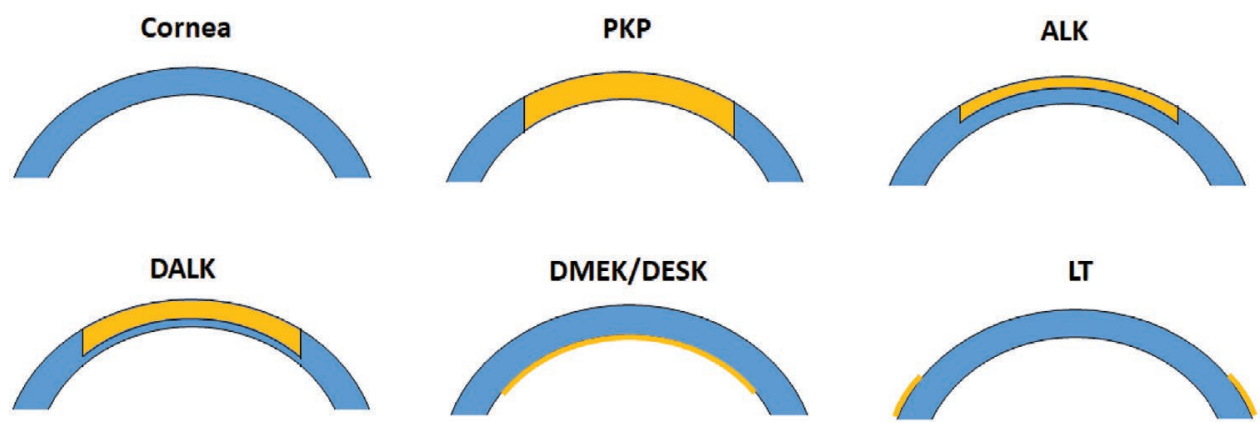

Figure 2. Schematic representation of the different types of keratoplasty. The blue section represents the original cornea and yellow represents the transplanted cells or tissue (PKP = penetrating keratoplasty, ALK = anterior lamellar keratoplasty, DALK = deep anterior lamellar keratoplasty, DMEK = Descemets membrane endothelial keratoplasty; Descemets stripping endothelial keratoplasty, LT = limbal transplant). 
This technique has been shown to be capable of generating stromal tissue with good transparency and a fibril organization and matrix composition similar to that found in the native corneal stoma. ${ }^{[35]}$ The stroma formed is also capable of supporting epithelium and endothelium formation. The main limitations with this approach are the time taken to culture sufficient number of cells and the limited thickness of the stromal tissue with reports suggesting a culture time of 4-5 weeks to generate $50 \mu \mathrm{m}$ thick stroma. Research by the Zeugolis lab has shown that the stromal tissue formation process by cells can be accelerated using macromolecular crowding, a technique that reduces the amount of procollagen being washed away in the cell culture medium. ${ }^{[36]}$ A simple method of overcoming the issues with thickness could potentially be resolved by stacking multiple stromal sheets, ${ }^{[37]}$ although the success of the implant would be dependent on how well the layers integrate with each other. The integration of the layers is particularly important for PKP and DLKP where multiple layers would be required and there is a danger of slippage between layers leading to degradation. The self-assembly of cells has also been used to generate epithelium on a temperature responsive carrier material that allows the detachment of the cells from the material without the need for enzymes. ${ }^{[38]}$ Since the focus of this paper is on corneal scaffold design, the proceeding sections will concentrate on scaffold-based solutions rather than the bottom-up approach.

\subsection{Scaffold Physical Properties}

To determine the suitability of a scaffold for corneal regeneration or replacement, it is important to understand how cells will interact with the scaffold both in vitro and in vivo. Factors such as cell adhesion, morphology, migration, proliferation, and extracellular matrix production are all influenced by the physical and chemical properties of the scaffold. Several studies have shown that the stiffness of a material can influence the phenotype of many different cell types including corneal epithelial cells, ${ }^{[39]}$ limbal derived stem cells, ${ }^{[40]}$ corneal stromal cells, ${ }^{[41]}$ and corneal endothelial cells. ${ }^{[42]}$ For stromal derived cells, culture on a low stiffness appears to reduce transforming growth factor $\beta 1$ (TGF- $\beta 1$ ) induced myofibroblastic differentiation. ${ }^{[41 a, 43]}$

In addition to affecting how cells behave, mechanical properties of the scaffolds are also important for functional reasons. The scaffolds must be sufficiently stiff and strong to be able to withstand suturing without tearing and withstand physiological forces applied to it postimplantation such as intraocular pressure, eyelid motion, and tear film motion. ${ }^{[4]}$ If the scaffold is insufficiently stiff or strong, it could undergo deformation or failure, respectively. The scaffold stiffness should also not be too high, as this would reduce its ability to deform in the same way as the surrounding tissue when under stress and potentially lead to a mismatch in strain. The viscoelastic characteristics of cornea also have to be considered as these influence the behavior of the cornea under load. ${ }^{[45]}$ Ideally, the scaffold mechanical properties should match the native corneas as close as possible. Young's modulus and tensile strength of cornea varying considerable between publications (modulus $\approx 100 \mathrm{kPa}$ to $57 \mathrm{MPa}$; strength $\approx 3-6 \mathrm{MPa}$ ) due to the tissue anisotropy, different testing mechanisms and donor variability. ${ }^{[46]}$ Corneal permeability $\left(\approx 2.2 \times 10^{-18} \mathrm{~m}^{4} \mathrm{~N}^{-1} \mathrm{~s}^{-1[47]}\right)$ is another factor that is often overlooked when designing scaffolds but is vital for allowing nutrients and gases into the central cornea.

Another factor that will influence how cells behave is the structure of the scaffolds. In vivo corneal stromal cells reside between layers of aligned collagen fibrils. To examine how these cells response in vitro to such topographical cues, channels with widths and depths in the micrometer and nanometer ranges have been used. Aligned substrates were found to increase corneal stromal cell alignment, direct cell migration and promote a keratocyte phenotype ${ }^{[48]}$ Similarly, channels that mimic the nanostructure of the corneal basement membrane, ${ }^{[49]}$ have been shown to affect corneal epithelial cells elongation, adhesion, proliferation, and gene expression. ${ }^{[48 d, 50]}$ Scaffolds have also been developed to study the effect of topographical cues on corneal cells in a 3D environment since this is more physiologically relevant. Wilson et al. showed that incorporating aligned nanofibers into a hydrogel increased expression of keratocyte specific genes and reduced expression of myofibroblastic genes. ${ }^{[51]}$ In addition to surface topography, it has recently been shown that surface curvature can also influence the orientation and phenotype of corneal stromal and epithelial cells. ${ }^{[52]}$

In addition to the scaffold affecting how the cells behave, reciprocally, cells can remodel the scaffold through the application of strain and the release of enzymes and extracellular matrix molecules. ${ }^{[53]}$ It is therefore important that the scaffold supports the cells to remodel it into a tissue that resembles real cornea. Ideally, as the scaffold degrades ECM molecules should replace the structure without compromising its integrity or functionality. Generation of aligned collagen fibrils in the stroma while remodeling is important for corneal transparency and may be assisted by initially aligning the scaffold in a similar pattern. For example, low concentration collagen hydrogels seeded with corneal fibroblasts undergo contraction and form an opaque sphere unless tethered to a support structure such as a ring. ${ }^{[53]}$ Factors such as seeding density, culture media composition, biomaterial degradation resistance, material concentration in hydrogels, porosity, and structure can be optimized to control the remodeling process. Some scaffolds may be designed to avoid remodeling and degradation and instead provide a stable implant that does not change over time. While this has some advantages, including lower risk of uncontrolled degradation and reduced susceptibility to donor/patient variability over long time periods, these implants would likely fail due to the lack of regeneration occurring. Hence, scaffolds that support remodeling and regeneration have more potential as corneal substitutes.

The phenotype of the cells is another important factor, particularly for stromal remodeling with quiescent keratocytes being noncontractile and producing minimal matrix components, while myofibroblasts are highly contractile and produce different proteins and matrix metalloproteinases (MMPs). ${ }^{[54]}$

The biocompatibility of the scaffold is important to ensure that it survives after implantation. The materials used to fabricate the scaffolds and their degradation products need to be noncytotoxic and not induce a host immune response. Keratoplasties are often considered to be immune privileged since there are no blood or lymphatic vessels in the cornea. However, despite having a lower 


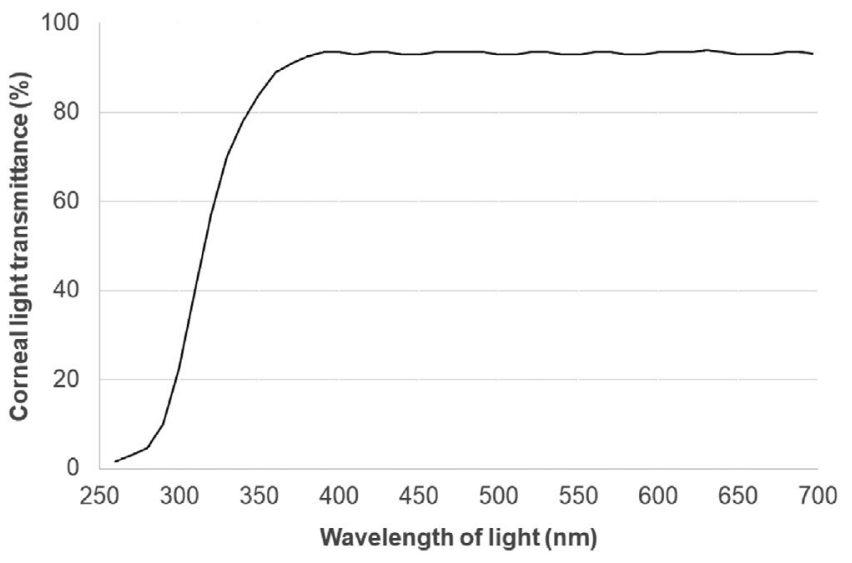

Figure 3. Image showing the transmittance of light through a cornea across different wavelengths.

immune rejection rate than many other tissues and organs, the implanted cornea can still illicit an immune response and undergo rejection. The risk of immune rejection increases with regrafts due to the initial severing of nerves leading to the loss of anterior chamber-associated immune deviation. ${ }^{[55]}$

\subsection{Optical Properties}

Another factor that needs to be considered when developing scaffolds for corneal regeneration is that the scaffolds need to have similar light transmittance characteristics to the real cornea. The cornea allows light from the visible light spectrum (wavelength $400-780 \mathrm{~nm}$ ) to pass through while limiting light in the ultraviolet (UV) spectrum (less than $400 \mathrm{~nm}$ ) as shown (Figure 3). The ability of UV light to pass though the cornea differs between the central and peripheral regions ${ }^{[56]}$ and UV exposure can result in damage to the retina. ${ }^{[57]}$ In addition, the cornea needs to be able to focus light through the lens into the retina. An improper curvature of the cornea (such as with astigmatism) can result in light not being focused correctly and lead to reduced vision.

The transparency of the cornea is dependent on its collagen fibril structure. The corneal stroma consists of small, aligned collagen fibrils with regular spacing between fibrils. ${ }^{[3]}$ This highly organized arrangement is believed to be vital to allow light to pass between the fibrils since any disruption of this organization due to injury or disease results in a reduction in transparency. ${ }^{[58]}$ The cells in the stroma also play a role in allowing visible light through the cornea. Crystalline proteins found in the cytoplasm such as ALDH1A1 and ALDH3A1 reduce the ability of keratocytes to scatter light. ${ }^{[5]}$ When these cells are activated, the presence of these proteins is reduced and the cells disrupt the passage of light.

\section{Materials Selection}

\subsection{Collagen}

Collagen type I is the most abundant protein in the cornea with lesser amounts of other collagens also present. ${ }^{[3,60]}$ Collagen
Table 3. Summary of collagen-based scaffolds.

\begin{tabular}{|c|c|c|c|}
\hline Application & Scaffold material & Tested in vivo & Refs. \\
\hline Epithelial & Rat collagen I & No & [64] \\
\hline Epithelial & Bovine collagen I & No & {$[61,65]$} \\
\hline Epithelial & Bovine collagen I & Rabbit & [66] \\
\hline Epithelial & Recombinant human collagen III & No & [67] \\
\hline Epithelial & Recombinant human collagen III & Mini-pig and rabbit & [68] \\
\hline Epithelial & Porcine collagen I+ GAC & No & [69] \\
\hline Epithelial and stroma & Porcine collagen I & Rabbit & [70] \\
\hline Epithelial and stroma & Rat collagen I & Rabbit & [71] \\
\hline Epithelial and stroma & Bovine collagen I & Rabbit & [72] \\
\hline Epithelial and stroma & Bovine collagen I & Dog & [73] \\
\hline $\begin{array}{l}\text { Epithelial, stroma, } \\
\text { and endothelium }\end{array}$ & Rat collagen I + GAG & No & [74] \\
\hline $\begin{array}{l}\text { Epithelial, stroma, } \\
\text { and endothelium }\end{array}$ & Bovine collagen I & No & [63] \\
\hline Stroma & Rat collagen I & No & {$[53,75]$} \\
\hline Stroma & Rat collagen I & Rabbit & [76] \\
\hline Stroma & Rat collagen I + PA & No & [77] \\
\hline Stroma & Bovine collagen I & No & {$[47 a, 78]$} \\
\hline Stroma & Bovine collagen I & Pig & [79] \\
\hline Stroma & Porcine collagen I & Guinea pig & [80] \\
\hline Stroma & $\begin{array}{l}\text { Recombinant human collagen I } \\
\text { and III }\end{array}$ & Mini-pig & [81] \\
\hline Stroma & Recombinant human collagen III & No & [82] \\
\hline Stroma & Recombinant human collagen III & Human & [83] \\
\hline Endothelium & Rat collagen I & No & [84] \\
\hline Endothelium & Bovine collagen I & Rabbit & [85] \\
\hline Endothelium & Porcine collagen I & Rabbit & [86] \\
\hline Endothelium & Human collagen I & Rabbit & [87] \\
\hline
\end{tabular}

forms a triple helix molecule containing repeating units of the amino acids glycine, proline, and hydroxyproline. In total, collagen constitutes $\approx 70 \%$ of the dry weight of the cornea. ${ }^{\left[{ }^{16}\right]}$ For this reason, collagen has been a popular choice of material to manufacture scaffolds that mimic the native cornea's composition. Some of the earliest attempts at engineering corneal tissue used collagen scaffolds and hydrogels. For example, Germain et al. used collagen to engineer the anterior segment of the cornea. ${ }^{[62]}$ Orwin and Hubel described the development of a collagen sponge that could support the growth of corneal epithelial, stromal, and endothelial cells. ${ }^{[63]}$ However, despite these promising early studies, a number of challenges were evident including poor mechanical properties (Young's modulus of collagen sponge $\approx 95-370 \mathrm{~Pa}^{[47 a]}$ ) and scaffolds not mimicking the stroma's native fibril organization. Numerous studies have since explored different methods of overcoming these issues and used collagen as their primary material for fabricating corneal scaffolds (summarized in Table 3).

Many collagen scaffolds have inferior mechanical properties and degradation resistance when compared to the native tissue. ${ }^{[78 a]}$ This is often due to a lower density of collagen being used to generate a scaffold compared to the collagen density in 
real cornea and a lack of crosslinks between collagen fibers in the scaffolds. To overcome this problem, different crosslinking treatments have been explored. Chemical crosslinking by glutaraldehyde, 1-ethyl-3-(3-dimethyl aminopropyl) carbodiimide hydrochloride (EDC) and multifunctional dendrimers have been shown to significantly increase the modulus and strength of collagen-based scaffolds (Young's modulus increased to 1.4 MPa after dendrimer crosslinking). ${ }^{[61]}$ The main limitation with these treatments is that these chemicals are cytotoxic so crosslinking can only be done on acellular scaffolds. Genipin has been suggested as a less cytotoxic alternative to crosslinking with glutaraldehyde, ${ }^{[88]}$ however at the concentrations needed to significantly increase mechanical properties, it results in collagen scaffolds turning a dark blue color. ${ }^{[89]}$ Crosslinking collagen with UVA light in the presence of riboflavin has been shown to increase the modulus of collagen hydrogels seeded with corneal stromal cells. This approach also led to a reduction in cell viability, albeit some viable cell remain after the treatment. ${ }^{[0]}$ The addition of peptide amphiphiles (PAs) to collagen has been shown to control contraction to enable a curvature to be generated. ${ }^{[7]}$

Different types of collagen scaffolds have been developed for corneal tissue engineering including hydrogels, films and sponges. Collagen hydrogels usually have a very high water content (up to $99.7 \% \mathrm{v} / \mathrm{v}$ ) but unlike many other hydrophilic hydrogels that are incompressible, the water content of collagen hydrogels can be reduced under compression, thus allowing the collagen concentration and hydrogel stiffness to be controlled. ${ }^{[1]]}$ Collagen films can be used to expand and transplant epithelial or endothelial cells ${ }^{[72,84 b]}$ or can be stacked to form multiple layers that mimic the stroma. ${ }^{[75 b]}$ Collagen sponges tend to have poor transparency compared to films or hydrogels and are believed to promote a myofibroblastic phenotype in stromal derived cells. ${ }^{[78 c]}$

The source of collagen plays an important role in dictating the scaffold's physical and biological properties. Collagen used for manufacturing corneal scaffolds is usually derived from animal tissues such as bovine or porcine skin or rat-tail or porcine tendon. The species and tissue from which the collagen is taken can affect the final physical properties of the scaffolds. ${ }^{\text {[92] }}$ The amino acids in collagen can vary between different species, which in turn affects the collagens overall characteristics. ${ }^{[93]}$ The modulus of collagen hydrogel scaffolds has also been shown to be dependent on the age of the animal from which the collagen is derived. ${ }^{[94]}$ Recently alternative sources to animal tissue have been investigated due to the potential risk of cross species disease transmission. Human derived collagen from bone chips has also been used for corneal tissue engineering, although the supply of such tissue is more limited than using animal derived collagen. ${ }^{[87]}$ As a potentially safer alternative to animal collagen, recombinant human like collagen can be manufactured from specific plants, bacteria, and yeast cells. ${ }^{[95]}$ This approach reduces the potential of disease transmission and should improve the consistency of the collagen produced since there are no donor variations. Transgenic animals may also be modified to secrete human like collagen in milk or other fluids. ${ }^{\text {96] }}$

In addition to the collagen source, the type of collagen needs to be considered when producing a corneal scaffold. While the majority of studies have used type I collagen since this is the most widely available and the most abundant collagen in the stroma, other studies have focused on different types of collagen to generate scaffolds. For example, recombinant collagen type III has been shown to be suitable for manufacturing artificial stroma with similar optical properties and structure to the native stroma. ${ }^{\left[{ }^{[2]}\right.}$ Merrett et al. and Lagali et al. found that type I and type III recombinant collagen scaffolds had similar physical properties to the corneal stroma and produced a similar cell response when used as a stromal replacement. ${ }^{[81]}$ Clinical data suggests that recombinant collagen III implants remain stable and transparent for several years without inducing any negative side effects and could be used to treat patients with severe corneal damage. ${ }^{83]}$

Collagen scaffolds can be processed in a number of different ways to give very different properties. One type of collagen scaffold that has been under investigation for corneal tissue engineering is referred to as a vitrigel. ${ }^{[97]}$ This is a collagen hydrogel that has been vitrified and then rehydrated. Vitrification involves the slow dehydration of the hydrogel at a predetermined temperature to form a rigid glassy material. The result is a mechanically strong and stable material with good optical properties. ${ }^{[98]}$ Vitrigels have been used to grow and transplant corneal epithelium ${ }^{[66]}$ and endothelium ${ }^{[86}$ in animal models. More recently, the material has been used to manufacture ocular permeability and irritancy assays to assess the safety of chemical and pharmaceutical products. ${ }^{[99]}$ One potential limitation with this material is that it is unclear how well corneal stromal cells migrate into the vitrigel, which might limit its applications as a stromal replacement.

One alternative approach to generating collagen scaffolds with aligned fibers and low immunogenicity is to use fish scales. Scales from the tilapia have been decellularized and decalcified to leave an organized, biocompatible collagen type I matrix. ${ }^{[100]}$ These scaffolds have been tested intrastromally in vivo using rats ${ }^{[101]}$ and rabbits. ${ }^{[100 a, 102]}$ In these studies, the scaffolds were acellular upon implantation so it is not clear if they can be populated with keratocytes in vitro prior to implantation. While scales from tilapia have been the most extensively studied, scales from other species of fish have also been used to produce collagen scaffolds. ${ }^{[103]}$ Fish scale derived scaffolds have also been used for culturing human corneal endothelial cells, however further modification of structure and surface chemistry is required before considering it as a potential cell carrier for endothelial cells. ${ }^{[104]}$

\subsection{Silk Fibroin}

Silk fibroin is a protein that has become a biomaterial of considerable interest for corneal tissue engineering and regeneration over recent years due to its biocompatibility, biodegradability, mechanical strength, transparency, and ability to be used in a wide variety of forms including hydrogels, sheets, fibers, and sponges as well as forming various nanomaterial structures. ${ }^{[105]}$ Several silk products have been clinically approved for use in Europe and North America including silk sutures, silk dressings, and surgical meshes. A summary of studies involving the application of silk fibroin for corneal regeneration is shown (Table 4). 
Table 4. Summary of silk fibroin scaffolds.

\begin{tabular}{|c|c|c|c|}
\hline Application & Scaffold material & Tested in vivo & Refs. \\
\hline Epithelial & Bombyx mori & No & [106] \\
\hline Epithelial & Bombyx mori or Antheraea pernyi & No & [107] \\
\hline Epithelial & Bombyx mori and RGD peptides or PDL & No & [108] \\
\hline Epithelial & Bombyx mori and PEG & Rabbit & [109] \\
\hline Epithelial and stroma & Bombyx mori & No & [110] \\
\hline Epithelial and stroma & Antheraea mylitta & Rabbit & [1111] \\
\hline Epithelial and stroma & Bombyx mori and chitosan & Rabbit & [112] \\
\hline Epithelial and stroma & Bombyx mori and collagen & Rabbit & [113] \\
\hline Stroma & Bombyx mori & No & [114] \\
\hline Stroma & Bombyx mori & Rabbit & [115] \\
\hline Stroma & Bombyx mori and RGD peptides & No & [116] \\
\hline Stroma & Bombyx mori and chitosan & Rabbit & [117] \\
\hline Stroma & Bombyx mori and RGD peptides & Rabbit & [118] \\
\hline Stroma & Bombyx mori, retinoic acid, and riboflavin & No & [119] \\
\hline Endothelium & Bombyx mori & No & [120] \\
\hline Endothelium & Bombyx mori & Rabbit & [121] \\
\hline Endothelium & Bombyx mori and aloe vera & Rabbit & [122] \\
\hline Endothelium & Bombyx mori and PLLA/PCL & No & [123] \\
\hline Endothelium & Bombyx mori and collagen & No & [124] \\
\hline Endothelium & Bombyx mori and beta-carotene & No & [125] \\
\hline Endothelium & Bombyx mori and glycerol & No & [126] \\
\hline
\end{tabular}

chitosan ${ }^{[12,117]}$ to improve cell attachment and proliferation. Crosslinking silk fibroin films using riboflavin and UVA light has been shown improve their adhesion to the ocular surface. ${ }^{[06 \mathrm{~g}]}$ Bioactive molecules, such as retinoic acid, have also been incorporated into silk fibroin to regulate the phenotype of corneal stromal cells. ${ }^{[119]}$

Silk fibroin provides a useful substrate to incorporate topographical cues that can deliberately influence cell behavior. As stated previously, microgrooves and nanogrooves have been shown to direct cell migration and affect cell phenotype. These patterns can be imprinted onto silk fibroin using lithography or casting techniques. Patterned silk fibroin has been used to examine the influence of topographical channels on epithelial cell phenotype, ${ }^{[50 a]}$ epithelial migration, ${ }^{[106 \mathrm{e}]}$ limbal cell adhesion and cytoskeletal organization, ${ }^{[106 \mathrm{~d}]}$ and limbal cell differentiation. ${ }^{[128]}$ Stromal stem cells and fibroblasts have also been cultured on pattern silk fibroin films and stacked to generate a stromal equivalent. ${ }^{[114 e]}$

Silk fibroin films have been shown to act as a useful carrier of corneal epithelial and limbal cells due to their permeability, transparency, strength, and thickness. In several studies, silk fibroin has been combined with

Silk fibroin derived from Bombyx mori cocoons has been the most extensively evaluated for use in engineering cornea. These silkworms are commonly used to produce silk for clothes, hence the cocoons are much cheaper than other sources. Hogerheyde et al. explored the use of silk fibroin derived from Antheraea pernyi cocoons for culturing and transplanting corneal epithelial cells but found the material to be less transparent and more brittle than B. mori fibroin. ${ }^{[107]}$ Hazra et al. examined the use of Antheraea mylitta cocoons to isolate fibroin for corneal regeneration. ${ }^{[11]}$ This study showed that $A$. mylitta derived fibroin was transparent, supported cell growth, and was nonimmunogenic when implanted into the corneal stroma of rabbits. However, the study did not compare the fibroin directly to $B$. mori fibroin so it is unclear if $A$. mylitta fibroin has any additional benefits or limitations. One benefit might be that A. mylitta fibroin is chemically different from $B$. mori and contains arginyl-glycylaspartic acid (RGD) peptides that enhance cell adhesion. ${ }^{[127]}$ Silk fibroin isolated from other sources such as spider silk has to date not been examined for corneal tissue engineering or regeneration.

Several studies have modified $B$. mori silk fibroin by adding other molecules to alter its chemical properties and how it interacts with cells. For example, several studies have added RGD peptides to improve cell adhesion and spreading on fibroin. However, Jia et al. found that the addition of RGD to fibroin led to an increase in hydrophobicity and therefore suggested the addition of poly-D-lysine (PDL) to fibroin as an alternative approach to improve cell adhesion. ${ }^{[108]}$ Silk fibroin has also been blended with other biomaterials such as collagen or other materials (such as polyethylene glycol (PEG) or RGD peptides) to enhance cell adhesion. Changes to the surface topography have also been shown to enhance the adhesion of limbal cells, ${ }^{[106 \mathrm{~d}]}$ promote migration in a specific direction, ${ }^{[106 \mathrm{e}]}$ and regulate the cell's phenotype. ${ }^{[50 a]}$

The high Young's modulus (6-8 $\mathrm{GPa}^{[129]}$ ), flexibility, and ability to form thin films make silk fibroin a particularly attractive material for engineering corneal endothelial grafts. Madden et al. were one of the first groups to demonstrate that corneal endothelial cells could be cultured on silk fibroin films and maintain their cellular morphology. ${ }^{[120]}$ Similar silk fibroin films seeded with rabbit endothelial cells have been successfully transplanted in vivo using rabbits. ${ }^{[121]}$ No inflammation or immune rejection was detected and the grafts completely integrated with surrounding corneal tissue 6 weeks after implantation. Other studies have combined silk fibroin with other materials or chemicals such as lysophosphatidic acid, ${ }^{[130]}$ aloe vera, ${ }^{[122]}$ glycerol, ${ }^{[126]} \beta$-carotene, ${ }^{[125]}$ poly- $\varepsilon$-caprolactone (PCL) or poly-L-lactic acid (PLLA), ${ }^{[123]}$ and collagen ${ }^{[124]}$ to manufacture films suitable for generating an endothelial graft. The most common reasons for combining silk with other materials was to improve cell adhesion, cell proliferation, and $\mathrm{Na}^{+} / \mathrm{K}^{+}$adenosine triphosphatase (ATPase) pump function. For example, 4 weeks after implantation into rabbits, silk fibroin films combined with aloe vera appeared to have superior cell retention and more tight junctions between cells compared to films without aloe vera. ${ }^{[122]}$

A number of studies have used silk fibroin to generate in vitro models of the cornea to study cell behavior, assess ocular 
toxicity or model disease. Wang et al. developed a model to study nerve regeneration into a cornea. ${ }^{[110 b]}$ Several layers of silk fibroin were seeded with corneal stromal cells and combined using a collagen hydrogel. This portion of the construct was then covered with epithelial cells. Dorsal root ganglion neurons were then encapsulated in a silk sponge along the outer rim of the construct and the nerve growth into the central construct was monitored via immunofluorescent staining. Using a similar model, Deardorff et al. developed a diabetic corneal neuropathy model to study the effect of increases in glucose on corneal nerves. ${ }^{[131]}$

In addition to fibroin, silk also contains a protein called sericin that is usually discarded as a waste product during the fibroin extraction process. During the degumming process of silk cocoons, small peptides of sericin can be obtained. The fraction of sericin extracted differs depending on the extraction method used. ${ }^{[132]}$ Urea extraction resulted in water-soluble fractions while fractions obtained using other extraction methods tended to form hydrocolloids. ${ }^{[133]}$ However, to prevent degradation of the protein, Chirila et al. have suggested a slow, mild extraction process. ${ }^{[134]}$ Purified sericin has been used to increase the corneal wound healing rate in rats. ${ }^{[135]}$ The rate of wound healing was restricted by addition of an ERK inhibitor, implying that sericin is responsible for phosphorylation of ERK1/2. In a separate study, when compared to silk fibroin, sericin and sericin-fibroin composites had inferior mechanical strength and stiffness but enhanced adhesion of corneal limbal cells. ${ }^{\text {[136] }}$ One limitation with using sericin is its cytotoxicity, although this appears to be dependent on the extraction process. For example, the cytotoxicity of sericin extracted using urea was found to be significantly higher compared to other extraction methods. ${ }^{[133]}$ In contrast, other studies have found that sericin is immunologically inert ${ }^{[137]}$ and potentially anti-inflammatory due to its antiproliferative effects. ${ }^{[138]}$

\subsection{Amniotic Membrane}

One of the most commonly used natural biopolymers for corneal regeneration is the amniotic membrane isolated from placentas following caesarean section. It has been used for a variety of ophthalmological applications including the treatment of corneal burns and persistent epithelial defects. ${ }^{[139]}$ The tissue has also been used as a carrier for ex vivo expansion of limbal epithelial cells or grafted directly onto the cornea where it can integrate with the host tissue. ${ }^{[140]}$ The feasibility of using amniotic membranes for transplantation of endothelial cells has also been explored. ${ }^{[141]}$ The anti-inflammatory properties as well as high biocompatibility make amniotic membrane an attractive natural biopolymer for regenerating the corneal surface. However, limitations including availability of tissue, donor variability, uncontrolled degradation and issues associated with the improper storage and processing of membranes has led to an increased demand for alternative biomaterials to treat defects of the corneal epithelium. ${ }^{44]}$ The mechanical strength of the membranes can be improved by the incorporation of a nanofiber mesh as a support scaffold. ${ }^{[142]}$ To overcome storage limitations, the membranes can be freeze-dried and then rehydrated by a surgeon just before surgery. ${ }^{[143]}$

\subsection{Natural Biopolymers}

In addition to silk fibroin, collagen, and amniotic membrane, several other natural biopolymers have been explored for use in corneal regeneration. Many of these natural biopolymers have attractive properties including good biocompatibility, low immunogenicity, noncytotoxic degradation products, easily modified degradation rate in a biological system, and overall availability of materials. ${ }^{[144]}$ A table summarizing the different natural biopolymers that have been used for fabricating corneal scaffolds is shown below (Table 5).

\subsubsection{Gelatin}

Gelatin is a natural protein derived from the hydrolysis of collagen and has been used in many tissue engineering applications including the cornea. ${ }^{[165]}$ Among the properties that make gelatin an attractive material include its biocompatibility, low cost, and low immunogenicity. ${ }^{[166]}$ However, gelatin lacks
Table 5. Summary of natural biopolymer scaffolds.

\begin{tabular}{lccc}
\hline Application & Scaffold material & Tested in vivo & Refs. \\
\hline Epithelial & Gelatin + collagen I + hyaluronic acid & No & {$[145]$} \\
Epithelial & Gelatin + chitosan & No & {$[146]$} \\
Epithelial & Gelatin + chitosan + hyaluronic acid & Rabbit & {$[147]$} \\
Epithelial & Alginate & No & {$[148]$} \\
Epithelial & Hyaluronic acid & No & {$[149]$} \\
Epithelial and stroma & GelMA & Rabbit & {$[150]$} \\
Epithelial and stroma & Hyaluronic acid & No & {$[151]$} \\
Epithelial and stroma & Fibrin + agarose & Human & {$[152]$} \\
Epithelial, stroma, and endothelium & Fibrin + agarose & Rabbit & {$[153]$} \\
Stroma & Gelatin & Rabbit & {$[154]$} \\
Stroma & Gelatin + GAC & Rabbit & {$[155]$} \\
Stroma & Gelatin + collagen I & No & {$[156]$} \\
Stroma & GelMA & No & {$[157]$} \\
Stroma & Fibrin + fibronectin & No & {$[158]$} \\
Stroma & Alginate & No & {$[159]$} \\
Endothelium & Gelatin & No & {$[160]$} \\
Endothelium & Gelatin & Rabbit & {$[161]$} \\
Endothelium & GelMA & Rabbit & {$[162]$} \\
Endothelium & Hyaluronic acid & No & {$[163]$} \\
Endothelium & Hyaluronic acid & Rabbit & {$[164]$} \\
\hline
\end{tabular}


thermal stability ${ }^{[167]}$ and undergoes degradation quickly unless chemically crosslinked or combined with another material. The most common methods of crosslinking gelatin involve using carbodiimide (EDC) and N-hydroxysuccinimide (NHS) ${ }^{[145,155 b, 156]}$ or glutaraldehyde, although other methods have also been examined. ${ }^{[166]}$ Alternatively, gelatin can be chemically modified using methacrylic anhydride to form GelMA, a material that can undergo crosslinking via exposure to UVA light. ${ }^{[168]}$ Unlike most chemical crosslinking processes that are cytotoxic, the main advantage of using GelMA is that the cells can be mixed into the material prior to crosslinking. GelMA has been used to engineer stromal scaffolds, ${ }^{[157]}$ endothelial sheets, ${ }^{[162]}$ and as a corneal bioadhesive. ${ }^{[169]}$ Gelatin has also been combined with other materials to improve its mechanical properties, cell response and degradation rate including collagen, chitosan, chondroitin sulfate, and hyaluronic acid. ${ }^{[145-147,155 b, 156]}$

Due to its isoelectric point allowing a polyion complex to be formed, gelatin has been used as delivery vehicle for growth factors or other biomolecules. ${ }^{[170]}$ Isoelectric point and $\mathrm{pH}$ can vary depending on the source of gelatin and how it is processed so it is important to select a suitable type of gelatin for a particular application. ${ }^{[161 b]}$ In one study, ascorbic acid was incorporated into gelatin in the form of a cryogel for corneal stroma engineering. ${ }^{[154 b]}$ Ascorbic acid is known to increase cell proliferation, enhance collagen deposition, and regulate the phenotype of keratocytes. ${ }^{[26 a, 171]}$ An alkali burn animal model was used to demonstrate that intrastromal implantation of the constructs improved matrix regeneration, transparency, and decreased corneal damage.

Gelatin has been used to fabricate sheets for culturing and transplanting endothelial cells. ${ }^{[160,161]}$ When compared to atelocollagen sheets, gelatin displayed greater transparency, mechanical properties, and permeability for endothelial cell transplantation. ${ }^{[160]}$ Normal expression of functional endothelial phenotypic markers was observed on gelatin hydrogels. This study suggested that gelatin hydrogel sheets could be used for the transportation of corneal endothelial cells during transplantation.

In addition to using gelatin as a scaffold for engineering cornea or a sheet for transplanting cells, it can be used to manufacture bioadhesive hydrogels to be used for sealing and repairing cornea following injury without the need for sutures. ${ }^{[169,172]}$ A chemically modified, UV crosslinkable gelatin based material called GelCORE has been developed that mimics native corneal stiffness, is highly adhesive, cytocompatible, and biodegradable. In vivo data showed that this hydrogel was able to seal corneal defects without the need for sutures and promoted re-epithelialization of the corneal surface. ${ }^{[169]}$

\subsubsection{Fibrin}

Fibrin is produced by combining fibrinogen and thrombin and has been used as an alternative to suturing for keratoplasties. Fibrin has also been used to transplant limbal tissue with the aim of decreasing operative time, improving patient comfort, and increasing the ease of technique for surgeons. ${ }^{[173]}$ However, an in vitro study showed that the use of fibrin on explants significantly delayed corneal epithelial migration by acting as a physical barrier and should therefore be used with care to ensure the glue does not wrap around the explant. ${ }^{[174]}$ Recently, fibrin has been used in the form of a glue for sealing corneal wounds and leaks that have persisted after surgery as well as damage caused by trauma. ${ }^{[175]}$ The fibrin glue could be injected into the anterior chamber to seal any leaks postoperatively. However, the small number of cases used in this study as well as alternative interventions that are simpler and just as effective limits its use in this manner. A similar study used fibrin tissue glue to treat complex epithelial ingrowth after LASIK surgery. ${ }^{[176]}$ After removal of epithelial ingrowth with adjunctive fibrin glue, the recurrence of ingrowth was absent in $91.7 \%$ of eyes and visual acuity improved.

Fibrin combined with agarose has been used to engineer cornea. ${ }^{[152 a, 153,177]}$ The presence of agarose mechanically stabilized the hydrogel, improved transparency, and slowed degradation. The hydrogel is able to support the growth of corneal epithelial, stromal, and endothelial cells. ${ }^{[153]}$ Clinical trials are ongoing to examine the safety and feasibility of using this material for anterior lamellar keratoplasty. ${ }^{[152]}$

Fibrin combined with fibronectin has been used to form an interconnected network similar to those seen during in vivo wound healing. ${ }^{[158]}$ In a collagen matrix, corneal fibroblasts move independently whereas the fibrin matrix induces an interconnected, collective mode of cell spreading that was aided by fibronectin patterning.

\subsubsection{Chitosan}

Chitosan is a polysaccharide derived from chitin obtained from crustaceans. This material has been used to generate scaffolds for a variety of tissues due to its biocompatibility, antimicrobial and anti-inflammatory properties, and nontoxic biodegradability. ${ }^{[178]}$ However, chitosan scaffolds have poor mechanical properties and they can degrade quickly, although the degradation rate can be modified. ${ }^{[179]}$ Chitosan is more commonly used in combination with other materials when being used to develop scaffolds for engineering cornea. For example, chitosan has been combined with gelatin alone or gelatin and hyaluronic acid to generate sheets for culturing and transplanting limbal and epithelial cells. ${ }^{[146,147]}$ Chitosan has also been combined with silk fibroin to generate a corneal stromal substitute. ${ }^{[12,117]}$

\subsubsection{Alginate}

Alginate is a natural biopolymer derived from seaweed that has been used for several medical and biological applications including tissue engineering, drug delivery, and cell encapsulation. ${ }^{[180]}$ It consists of $b$-D-mannuronic and $a$-L-guluronic acid chains, the ratio of which influences the material's physical properties. ${ }^{[181]}$ A hydrogel can be formed by dissolving sodium alginate powder and exposing it to a source of calcium (e.g., calcium chloride) that allows the sodium ions to be replaced by calcium ions. Since alginate lacks cell adhesion sites, the material needs to be modified or combined with other materials for corneal applications. For example, alginate has been used with gelatin nanofibers to generate a corneal stromal scaffold. ${ }^{[159]}$ 
The addition of nanofibers to the alginate hydrogel enhanced its mechanical properties and resulted in a Young's modulus similar to native cornea. Oxidized alginate has also been used to support the culture corneal epithelial cells. ${ }^{[148]}$ The stability and lack of binding sites in alginate have limited the number of studies that have used this material for engineering cornea.

\subsubsection{Hyaluronic Acid}

Hyaluronic acid or hyaluronan is a nonsulfated glycosaminoglycan (GAG) found in several tissues and has previously been used for cartilage repairs and skin regeneration ${ }^{[182]}$ but has also been used as a scaffold for engineering cornea. Koivusalo et al. demonstrated using a porcine organ culture model that modified hyaluronic acid based hydrogels seeded with adipose derived stem cells could be used to repair damaged cornea without the need for sutures. ${ }^{[151]}$ Hyaluronic acid has also been suggested as a suitable xeno-free substrate for culturing corneal epithelial cells $^{[149]}$ and as a potential carrier for endothelial cells. ${ }^{[163,164]}$ Despite some promising results, one potential limiting factor with using hyaluronic acid for corneal tissue regeneration is that the material has been associated with lymphangiogenesis in the limbus, although this requires further study. ${ }^{[183]}$

\subsection{Decellularized Cornea}

Organ decellularization consists of removing cells and their debris to obtain an acellular scaffold composed of just the organ's ECM. By removing the cells, major histocompatibility complexes are depleted thus reducing the risk of graft rejection. The main advantage of using decellularized corneas is that the obtained scaffold should be biochemically identical to original tissue. Furthermore, the exquisite collagen arrangement in the corneal stroma can be maintained, which is difficult to replicate using other biomaterials. The scaffolds should remain sterile throughout the decellularization process although terminal sterilization via gamma irradiation is often used to ensure sterility. ${ }^{[184]}$ In a recent study, researchers have demonstrated that gamma irradiation does not significantly disturb the architecture of the ECM. ${ }^{[185]}$ As with many materials, batch-to-batch variability can be expected due to donor variability. It is also important to ensure the corneas have been sufficiently decellularized. Macrophage polarization toward an M1-phenotype has been observed in vitro and in vivo when decellularization is incomplete. ${ }^{[186]} \mathrm{B}$ lymphocyte activation may also occur, as well as binding of immunoglobulins and complement proteins to residual cell components. ${ }^{[187]}$

A wide range of methods have been described to decellularize organs. In general, these methods can be divided into physical, chemical, and biological methods (Table 6). Most decellularization methods are based on a combination of different methods. Physical methods include agitation, freezethawing, ${ }^{[188]}$ high hydrostatic pressure, ${ }^{[189]}$ or supercritical $\mathrm{CO}_{2} \cdot{ }^{[190]}$ Chemical agents include detergents, such as sodium dodecyl sulphate (SDS), ${ }^{[191]}$ sodium deoxycholate (SDC), ${ }^{[184 f, 188 b]}$ Triton X-100, ${ }^{[192]}$ or lauroyl glutamate; ${ }^{[193]}$ organic acids, such as peracetic acid ${ }^{[194]}$ or formic acid;[195] bases, such as ammonium

Table 6. Summary of decellularized cornea studies.

\begin{tabular}{|c|c|c|c|c|}
\hline Application & Scaffold species & Primary decellularization technique & Tested in vivo & Refs. \\
\hline Epithelium & Human & Biological & Rabbit & [212] \\
\hline Epithelium & Porcine & Biological & Rabbit & [230] \\
\hline Epithelium & Human & Chemical & Rat & [231] \\
\hline Stroma & Porcine & Biological & Rabbit & [184b] \\
\hline Stroma & Porcine & Chemical & Dog & [184f] \\
\hline Stroma & Human & Biological & Rabbit & [198b] \\
\hline Stroma & Porcine & Physical & No & [225b] \\
\hline Stroma & Bovine & Chemical & No & [232] \\
\hline Stroma & Bovine & Physical & No & [190b] \\
\hline Stroma & Human & Chemical & Human & [210] \\
\hline Stroma & Human & Chemical & Rabbit & [201a] \\
\hline Stroma & Porcine & Biological & Rabbit & {$[184 \mathrm{e}, 199]$} \\
\hline Stroma & Porcine & Chemical & Human & {$[184 c, 213]$} \\
\hline Stroma & Porcine & Chemical & Nonhuman primate & [233] \\
\hline Stroma & Porcine & Physical & Rabbit & [234] \\
\hline Stroma & Human & Chemical & Rabbit & [205a] \\
\hline Stroma & Porcine & Chemical & Rabbit & [228] \\
\hline Stroma & Porcine & Chemical & No & [229] \\
\hline Endothelium & Human & Chemical & No & [192a] \\
\hline Endothelium & Human & Chemical & No & [208] \\
\hline Endothelium & Human & Physical & Cat & [188c] \\
\hline
\end{tabular}


hydroxide; $[192 \mathrm{a}, 196]$ and hypertonic solutions, mainly $1.5-2 \mathrm{M}$ sodium chloride. ${ }^{[188 a, 192 b, 197]}$ Biological methods used include commonly used cell dissociating agents, such as trypsin and dispase II; $\left.{ }^{[188 a}, 198\right]$ other catalytic enzymes, such as phospholipase A2;[184e,199] human serum; ${ }^{[200]}$ and nucleases, such as DNAses and RNAses. ${ }^{[184 f, 188 b, 201]}$ Each of these methods presents strengths and limitations, which have been highlighted previously. ${ }^{[202]}$ The main limitations with specific decellularization techniques may include insufficient removal of cells and DNA, loss of ECM components, disruption of the stromal matrix organization, and residual chemical agents remaining in the scaffold and affecting its biocompatibility. For this reason, optimization of the process is required.

Another factor that needs to be considered is the species from which the corneas are obtained. The ideal tissue source for corneal decellularization is human. While healthy corneas are usually transplanted to patients in need, some corneas are deemed unsuitable for transplantation due to low endothelial cell count or being positive for some viruses. In the case of low endothelial numbers, these corneas could potentially be repurposed for decellularization. ${ }^{[203]}$ In the case of infections, gamma irradiation could be used to eliminate the risk of bacterial, viral or fungal disease transmission. ${ }^{[204]}$ In addition, some studies have focused on the use of discarded tissue after small incision lenticule extraction (SMILE), a refractive technique for myopic treatment. ${ }^{[205]}$ While the use of human corneas is certainly one option, donor shortages remain an issue, thus alternative species have been explored.

Due to their anatomical similarities to human cornea and their availability, porcine corneas have been the most extensively studied for decellularization. Pig corneas are slightly thicker than human but have similar mechanical characteristics. ${ }^{[206]}$ In a recent study, it was found that the porcine cornea had the highest similarity score to the human, compared to 13 other animals that could be used for decellularization, among them were dog, cat, sheep, goat, cow, horse, and rabbit. ${ }^{[207]}$ This score was calculated from amino acid sequence, isoelectric point, and hydropathicity of the main ECM components found in the stroma. It is important to note that some immunogenic epitopes to humans are present in the porcine cornea, such as $N$-glycolylneuraminic acid (Neu5Gc) and galactose-alpha1,3 -galactose $(\alpha-\mathrm{Gal})$. This highlights the importance of applying a thorough decellularization process in order to avoid graft rejection.

Corneas can be decellularized as a whole or can be cut to a certain thickness by manual dissection or using a femtosecond laser-assisted cutting machine prior to decellularizatio n. ${ }^{[198 b, 208]}$ In some cases, researchers have opted to recellularize the scaffolds prior to implantation. For the recellularization of the stroma, the thickest layer of the cornea, the most common strategies have been injection ${ }^{[184 f, 188 b, 191 a, 209]}$ or simple seeding on the surface. ${ }^{[191 a, 197,210]}$ Injection can introduce cells into deeper areas of the tissue but can also result in fibril disruption. Seeding cells on the surface requires the cells to migrate into the densely packed collagen stroma. Seeding is more commonly used for the recellularization of the epithelium or endothelium since these cells are not required to migrate into the tissue, only to form a layer on the corneas anterior and posterior surfaces, respectively.
To evaluate decellularized corneal scaffolds, many studies have implanted them intrastromally by creating an intrastromal pocket and filling it with the scaffold. This approach provides some insight in the ability of the scaffold to integrate and elicit or inhibit strong immune responses. Recovery of transparency can also be assessed with this approach. Anterior lamellar keratoplasty is a more clinically useful model and provides information on the ability of the epithelium to regenerate on the surface of the scaffold. In a study by $\mathrm{Xu}$ et al., in vitro recellularized scaffolds with epithelial and stromal cells were shown to be beneficial in an ALK model in dogs. ${ }^{[184 f]}$ Other studies have shown that scaffolds without an epithelium still provided a good substrate for endogenous cells to repopulate the surface. ${ }^{[184 b, e, 211]}$

There have been a few novel approaches to generating corneal scaffolds that combine decellularization with other material fabrication techniques. For example, one approach has been to embed a decellularized lenticule in a compressed collagen I hydrogel to improve the hydrogel's mechanical properties, susceptibility to degradation and suturability, while maintaining its excellent cytocompatibility in an limbal epithelial stem cells deficiency model in rabbits. ${ }^{[212]}$ Decellularized corneas have also been studied as carriers for the transplantation of endothelial cells. ${ }^{[192 a, 208]}$ He et al. decellularized cornea lamellae obtained by femtosecond laser using different methods and found 1\% SDS with DNAse to be optimal. ${ }^{[208]}$ The lamellae were then recellularized with an endothelial cell line that adhered and formed a tight endothelium expressing $\mathrm{Na}^{+} / \mathrm{K}^{+}$ATPase and tight junctions. While the reports are promising, the Descemet's membrane was not present. The hypothesis is however, that the implanted cells will lay down their own Descemet's membrane over time.

Despite being a relatively young field, findings from in vitro and animal experiments have been translated to the clinic. There has been one study in human where thin sections of human corneas were decellularized and implanted into patients with keratoconus to increase their stromal thickness and delay the need for transplantation. ${ }^{[210]}$ Some patients received sections recellularized with ASCs but there was no significant benefit when compared to cell-free sections. Furthermore, Chinese company AiNear Corneal Engineering Co., Ltd. has a product based on dehydrated decellularized porcine corneas. It has been used to treat patients with fungal keratitis and herpes simplex keratitis, conditions that have a high risk of graft rejection. Overall, reports of the use of this product have been positive. ${ }^{[184 c, 213]}$ These scaffolds have recently been improved by controlling ionic and colloid osmotic pressure, thus reducing swelling and loss of transparency. This led to earlier improved visual acuity in patients with corneal ulcers, from bacterial, fungal or unknown origin. ${ }^{[193 a]}$ Other researchers have bypassed the decrease in transparency during decellularization by immersing the scaffolds in glycerol to further lyophilize them for storage. ${ }^{[214]}$

Hydrogels have been obtained from the solubilization of ECM by decellularizing tissues or organs, lyophilizing the remaining ECM, grinding this into a powder, and digesting in a suitable solution such as acidic pepsin or acetic acid. By neutralizing the $\mathrm{pH}$ of the solution and raising the temperature to $37^{\circ} \mathrm{C}$, fibrillation is induced. Hydrogels following this method 
have been obtained from many organs including urinary bladder matrix, ${ }^{[215]}$ dermis, ${ }^{[216]}$ pancreas, ${ }^{[217]}$ myocardium, ${ }^{[218]}$ skeletal muscle, ${ }^{[218 b]}$ demineralized bone, ${ }^{[219]}$ small intestinal submucosa, ${ }^{[220]}$ liver, ${ }^{[221]}$ cartilage, ${ }^{[222]}$ tendon, ${ }^{[223]}$ adipose tissue, ${ }^{[222]}$ and kidney. ${ }^{[224]}$ This approach allows for the injection of these hydrogels into the diseased site due to their shear thinning properties and opens the door for their use in 3D bioprinting. Hydrogels obtained from decellularized corneas have been reported in the literature ${ }^{[225]}$ and were first described by our group. ${ }^{[225 b]}$ Since these hydrogels are mechanically weak, postgelation crosslinking can be used to improve stiffness and strength. For example, using a UVA-riboflavin crosslinking technique, similar to the technique used clinically on patients suffering from keratoconus, has been shown to significant increase the modulus of corneal ECM hydrogels. ${ }^{[225 c]}$ The decellularization technique used also needs to be considered as this can have a significant effect on the hydrogel's final physical and biological characteristics. ${ }^{[226]}$ Kim et al. recently reported using decellularized cornea ECM for 3D bioprinting which resulted in a more transparent construct compared to using type I collagen. ${ }^{[225 a]}$

ECM particles have been incorporated into different biomaterials to generate scaffolds for several different types of tissue. The ECM is used to provide biochemical cues and support biological functions rather than construct a 3D environment. ${ }^{[227]}$ Recently tissue-derived microparticles from the lymph nodes, cartilage, and cornea were compared for their potential to improve corneal wound healing. ${ }^{[228]}$ In vitro these particles decreased TNF $\alpha$ and MMP9 expression by keratocytes induced by exogenous IL-1 $\beta$. In vivo experiments were performed using the lymph node particles as they showed better effects on epithelial and conjunctival cells. The particles were applied on an anterior lamellar keratoplasty model in a rabbit using fibrin glue as a carrier. In a subsequent study, the particles were applied to an ex vivo model of keratoconus, obtained by weakening the stroma with Chondroitinase ABC. ${ }^{[229]}$ The treatment improved mechanical properties, increased collagen fibril density, and promoted the expression of several keratocyte markers.

\subsection{Synthetic Polymers}

All the previously described polymers are derived from natural sources. Synthetically produced polymers have also been used for designing corneal scaffolds. Many polymers such as PCL and PLLA that have been used as scaffolds to engineer other tissues are normally considered unsuitable for cornea due to the lack of transparency, although they could be used to mechanically support other polymers. Polyvinyl-alcohol (PVA) is one transparent synthetic polymer that also has been shown to have good biocompatibility and good mechanical strength. ${ }^{[235]}$ To enhance cell adhesion and the bioactivity of the material, PVA has been combined with natural materials like cellulose, amniotic membrane, and collagen to generate scaffolds for corneal tissue engineering. ${ }^{[236]}$ PEG is another synthetic polymer that has been used in corneal scaffolds. PEG hydrogels have good biocompatibility, permeability, and transparency making them a potentially suitable material to replace cornea. More commonly, PEG is combined with another material to generate a corneal scaffold. Islam et al. reported conjugating a collagenlike peptide to PEG to generate a transparent hydrogel capable of promoting cell infiltration and nerve growth in vivo in a stromal mini-pig model. ${ }^{[237]}$

\section{Fabrication Processes}

\subsection{Bioprinting}

Bioprinting is an additive manufacturing technique that involves printing both cells and materials with the aim of generating viable, 3D tissues and organs. ${ }^{[238]}$ By printing layer upon layer of material, complex geometries to deal with patient specific problems can be achieved. There are a number of different techniques that can be used to bioprint tissues including extrusion, inkjet printing, laser assisted printing, and stereolithography (Figure 4), the advantages and limitations associated with each of these have been highlighted previously. ${ }^{[239]}$

There have been several different approaches to bioprint cornea and corneal components. One of the first reported uses of corneal derived cells in a bioprinted construct involved human corneal epithelial cells bioprinted inside alginategelatin-collagen based bioink. ${ }^{240]}$ Despite the high cell viability and the cells positive staining for the epithelial marker cytokeratin 3, the transparency of the final construct was poor. Corneal stromal constructs containing keratocytes have been bioprinted using various bioinks including alginate with methacrylated collagen, ${ }^{[241]}$ agarose blended with collagen, ${ }^{[242]}$ and corneal extracellular matrix. ${ }^{[225 a, 243]}$ Rather than using the conventional extrusion based bioprinting technique, Sorkio et al. used laser induced forward transfer to bioprint the anterior segment of the cornea. They used ESCs and laminin to fabricate the epithelium and ASCs and collagen to fabricate the stroma. ${ }^{[244]}$

While bioprinting has many advantages over other construct manufacturing techniques such as automation, reproducibility, and ability to print specific shapes, there are a number of limitations when the technique is applied to fabricating cornea. The main limitation associated with many of the bioprinted corneal constructs is their poor optical properties compared to real corneal tissue. While the bioink material being printed is usually transparent, the surface of the final printed construct is often rough resulting in an uneven refraction of light as it passes though the construct. This is a limitation of the printing process itself since to generate a curvature by printing flat layers, each printed layer needs to be slightly offset from the previous layer. The problem can be partially overcome by printing cylindrical rather than hemispherical corneal constructs although this introduces a new problem since the construct will probably differ in shape to the tissue it is replacing. ${ }^{[245]}$ Another potential limitation with bioprinting is the difficulty to replicate the collagen fibril organization found in the stroma. To overcome this problem, Kim et al. utilized the shear flow properties of the bioink during printing to direct fibrils in the desired orientations. ${ }^{[243]}$ The collagen fibrils in the bioink aligned in the direction that the needle was moving. Cells in these aligned constructs presented increased expression of keratocyte markers keratocan and ALDH. 

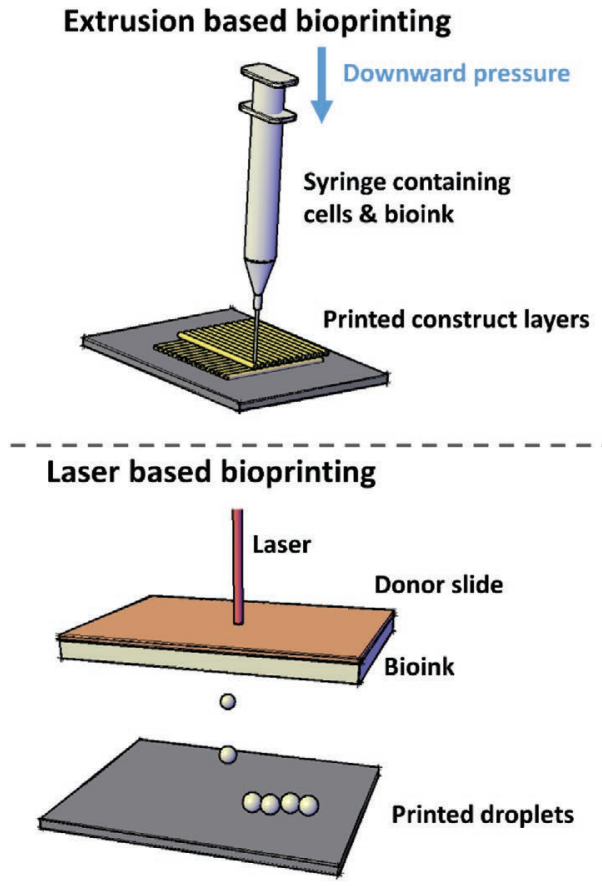

\section{Inkjet based bioprinting}

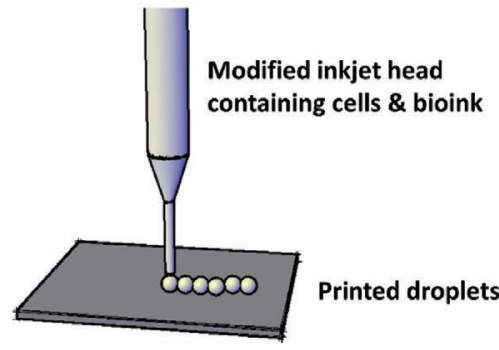

\section{Stereolithographic bioprinting}

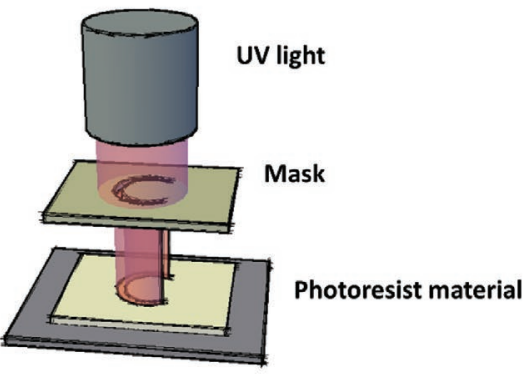

Figure 4. Schematic representation of different bioprinting techniques including extrusion-based bioprinting, inkjet bioprinting, laser-based bioprinting, and stereolithographic bioprinting.

\subsection{Electrospinning}

Electrospinning is another materials fabrication technique that can be used to generate scaffolds. ${ }^{[246]}$ In most cases, the scaffold material is dissolved in a solvent and extruded through a needle under a high electrostatic charge. This charge affects the surface tension of the solution leading to a thin jet being pulled toward a grounded or negatively charged collector. The solvent evaporates as the jet is moving toward the collector, resulting in the formation of micro- or nanofibers. This process is particularly attractive for generating corneal scaffolds since the fibers generated can theoretically mimic the collagen fibrils present in the stroma.

The type of collector used is vital to controlling the orientation of fibers produced during electrospinning. Examples of different types of collectors are shown (Figure 5). To replicate the corneal stroma, aligned sheets of fibers need to be produced and these sheets arrange in orthogonally orientated layers. Flat plate collectors are the most commonly used collectors for electrospinning but these result in fibers arranged in a random configuration. Rotating mandrels can be used to obtain more aligned fibers. As the mandrel rotates, the fibers are pulled around it resulting in a layer of fibers orientated around the cylinder. These can be detached and used to manufacture scaffolds. An alternative technique to produce aligned fibers is to use two parallel plates with sharp metallic edges. As the fibers are produced, they move between the two edges leading to the formation of aligned fibers. The fibers can be removed from the collector using cellulose frames that adhere to be fibers, allowing their orientation to remain fixed. ${ }^{[2 \mathrm{~b}, 51]}$ Radially aligned fibers can be produced using a cup and pin collector where the fibers align between the pin and outer circular ring (or cup). ${ }^{[247]}$ To obtain orthogonally orientated fibers a negatively charged collector connected to four separate posts can be used. ${ }^{[247]}$ The negative charge switches between the two horizontal posts and the two vertical posts at a specified rate. When the horizontal posts are charged the fibers are attached toward these and aligned horizontally between them. When the charge is switched to the vertical posts, fibers align vertically. This approach allows multiple layers of fibers to be formed with different orientations.

Several different materials have been used to generate electrospun scaffolds for corneal tissue engineering. Synthetic polymers such as PCL, PLLA, polymethyl methacrylate (PMMA), poly-L-D-lactic acid (PLDLA), polylactic-co-glycolic acid (PLGA), polyglycerol sebacate (PGS), and polyethyleneglycol diacrylate (PEGDA) have been investigated to determine their suitability for fabricating electrospun corneal scaffolds. ${ }^{[1,232,248]}$ These materials have better strength and degradation resistance than many natural polymers, however in most cases the materials lack transparency; therefore, sufficient spacing is required between fibers to allow light to pass through. Rather than generating full thickness corneal scaffolds, synthetic polymers are more suitable for generating thin electrospun sheets for epithelial ${ }^{[248 b, d]}$ or endothelial ${ }^{[248 a]}$ transplantation, as an alternative to amniotic membranes ${ }^{[249]}$ or as mechanical support for a stromal hydrogel material. ${ }^{[51]}$ Natural polymers including gelatin and collagen have been investigated for use in generating scaffolds for corneal regeneration. ${ }^{[250]}$ In the case of collagen, care needs to be taken in selecting a suitable solvent since many solvents result in denaturation of the collagen's triple helix molecule, resulting in the formation of gelatin. ${ }^{[159,251]}$ 

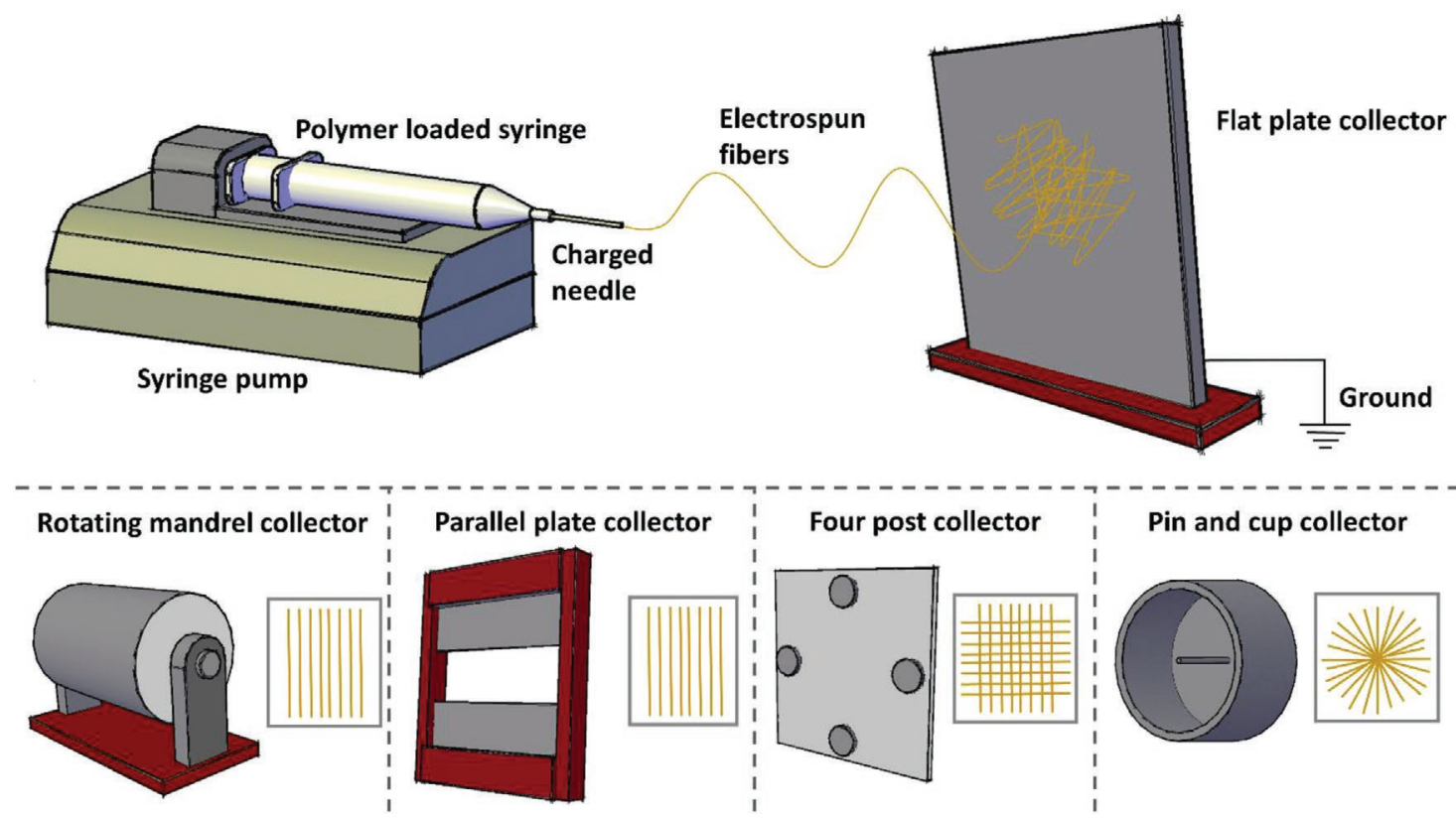

Figure 5. Schematic representation of the electrospinning process, examples of different types of collector, and the orientation of fibers produced using those collectors.

The main limitation with using electrospun natural polymers are their poor mechanical properties that make them more likely to be damaged during transplantation and difficult to handle. Several studies have combined natural and synthetic polymers to find an optimal combination of transparency, biocompatibility, and strength. Examples include combining PVA with collagen, ${ }^{[235 a]}$ PCL with collagen, ${ }^{\text {252] }}$ PLLA with gelatin, ${ }^{[253]}$ and PLLA and PCL with silk fibroin. ${ }^{[123]}$

One issue with producing scaffolds using electrospinning is how to keep the fibers together. The individual fibers produced during electrospinning are not crosslinked to each other so often an alternative method is needed to form a stable scaffold. One simple method is to encapsulate the fibers in a hydrogel. Wilson et al. demonstrated that aligned PLDLA fibers seeded with corneal fibroblasts could be encapsulated using a collagen hydrogel. ${ }^{[51]}$ Similarly, Tonsomboon and Oyen encapsulated gelatin fibers in an alginate hydrogel. ${ }^{[159]}$

Recently, there has been increasing interest in melt electrospinning. ${ }^{[254]}$ Rather than using solvents to dissolve the polymer, in melt electrospinning the polymer is heated into its viscous phase to allow it to be extruded through the needle. This process allows better control of the fiber architecture compared to solvent-based electrospinning, however the fibers formed are generally larger in diameter and the range of materials that can be used is more limited. Despite the potential of the technique to engineer various tissues and organs ${ }^{[255]}$ and generate scaffolds that modulate cell behavior, ${ }^{[256]}$ there have been no reports on its use for corneal applications.

There are a number of limitations associated with using electrospinning to generate corneal scaffolds. One of the main difficulties is trying to spin fibers that are similar in size to the collagen fibrils found in the stroma, $\approx 36 \mathrm{~nm}$ in diameter. ${ }^{[257]}$ The spacing between fibers is also difficult to control and is vital for maintaining corneal transparency. The pore size between fibers also needs to be considered, as this would need to be sufficiently large to allow cells to penetrate into the scaffold. Since most solvents used for electrospinning are cytotoxic, it is necessary to prove that no residual solvent remains before the scaffolds could be with patients. Electrospun scaffolds can also be fragile and difficult to handle which is a challenge if the scaffold needs to be implanted and sutured.

\subsection{Mechanical Manipulation}

One of the main limitations associated with many of the collagen and ECM-based hydrogels used for corneal regeneration is that they lack the collagen density and organization needed to mimic the cornea ECM physical properties in vivo. Collagen hydrogels have been shown to be easily remodeled by corneal stromal cells resulting in their contraction. ${ }^{[33]}$ In addition, the low collagen density lead to inferior mechanical properties compared to native corneal tissue. ${ }^{[75 a]}$ To overcome the limitations, a number of processing techniques have been developed that involve the application of either compressive or tensile forces.

Plastic compression is a simple technique that can be used to increase the density of collagen hydrogels. ${ }^{[91 a, 258]}$ It involves placing the hydrogel under an applied load that results in water being absorbed from the hydrogel, thus leading to a 100-200fold increase in collagen density ${ }^{[91 b]}$ (Figure 6A). A more recent variation of the technique involves using an absorber to remove water without a load needing to be applied ${ }^{[259]}$ (Figure 6B). Cells encapsulated within the hydrogels remain viable despite the force applied to their surrounding matrix. The result is a thin collagen structure that appears similar to many soft tissues. This technique has been used to generate corneal epithelial, ${ }^{[64 a]}$ stromal, and endothelial ${ }^{[260]}$ constructs. These scaffolds displayed good biocompatibility when inserted into a rabbit 


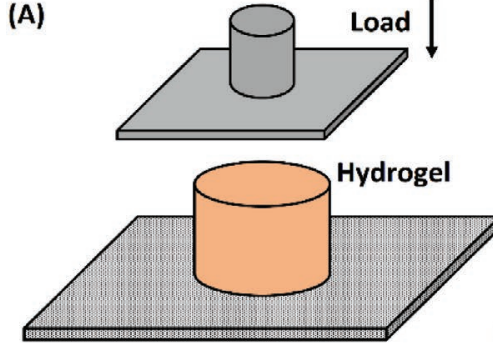

Absorbing mesh

(B)

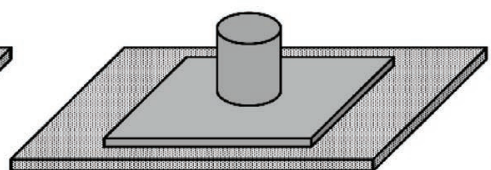

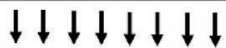
Water pushed out under load

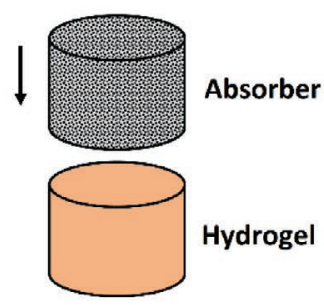

Absorber

Figure 6. Schematic representation showing plastic compression of a collagen hydrogel A) by the application of a load and B) by the application of an absorber.

stromal pocket. ${ }^{[76]}$ To improve transparency and reduce fibril diameter, Hong et al. used different mixtures of type I collagen and decellularized cornea ECM. ${ }^{[261]}$ To improve the integration of the scaffolds into the stroma, Rafat et al. combined plastically compressed collagen with a porous outer collagen skirt to generate an artificial stromal implant whose inner core was transparent and whose outer skirt could be used to transport cells or drugs. ${ }^{[70 b]}$ Kong et al. obtained a similar result by plastically compressing collagen onto electrospun PLGA to generate a physical support around the edge of the construct. ${ }^{[262]}$ Plastic compression has also been applied to generate biomimetic niches for limbal derived stem cells by preparing the collagen on a micropatterned surface. ${ }^{[263]}$

Plastic compression allows for collagen to be aligned in one plane only. Several methods have been investigated to induce the alignment of collagen in scaffolds and hydrogels (Figure 7). Static tensile strain or stretch of collagen hydrogels has been shown to result in collagen fibers orientating in parallel to the strain direction. ${ }^{[264]}$ The application of cyclical strain may also be used to align collagen perpendicular to the strain direction, ${ }^{[265]}$ although this would also lead to mechanotransduction and alter the phenotype of any cells present. ${ }^{[266]}$ It has previously been shown that corneal stromal cells respond to localized strains by altering focal adhesion to minimize strain effect on the cells. ${ }^{[41 b]}$ For cell-seeded collagen hydrogels, tethering the hydrogel at opposite ends would result in contraction and alignment of the hydrogel, [267] however, generating a sheet of material using this technique is challenging. Alternatively, the direction of flow can be manipulated to result in collagen alignment prior to gelation of these hydrogels. ${ }^{[268]}$ Finally, the negative diamagnetic anisotropy of collagen allows it to be aligned when subjected to a high magnetic field. ${ }^{[71,269]}$ While these techniques allow for alignment of collagen in one direction, multiple layers of aligned collagen sheets would need to be stacked to mimic the stromal fibril architecture.
Another approach to both compacting and aligning collagen to increase its density is by applying an electrochemical fabrication method. ${ }^{[78 b]}$ Based on the principles of isoelectric focusing, this approach works by placing a collagen solution in an electric field where a $\mathrm{pH}$ gradient in the collagen causes positively charged collagen molecules to align at the positive end of the field and negatively charged molecules at the negative end. The electric charge repels the collagen molecules thus leading to compaction of the hydrogel. The result was a stable, transparent hydrogel that supports the culture of keratocytes.

\section{Future Trends and Considerations}

A comprehensive overview of the different design considerations, materials, and processing techniques used for engineering corneal scaffolds has been provided. While each scaffold material has specific advantages and limitations, collagen-based scaffolds and decellularized ECM appear to show the most promise since they more accurately mimic the corneal stroma's native composition. While amniotic membranes are still the gold standard for epithelial regeneration, collagen films loaded with specific biochemical reagents could be manufactured to mimic the amniotic membranes without the drawback of donor variability or limited supply. For the endothelium, silk fibroin appears to have the most potential due to its ability to form thin, strong films that support endothelial growth. Fabrication processes such as electrospinning and bioprinting will need to undergo significant improvements before they are capable of manufacturing corneal scaffolds suitable for kertoplasty. Several corneal scaffolds are currently undergoing clinical trials so the next few years could see these therapies becoming more readily available to patients suffering corneal blindness.

There are many tissue engineering and regenerative strategies under investigation for other tissues and organs that 
(A)

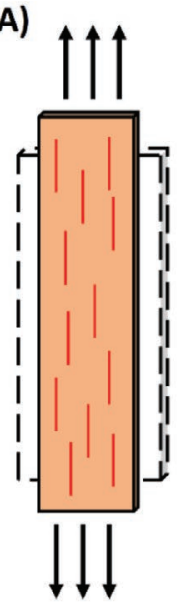

(B)

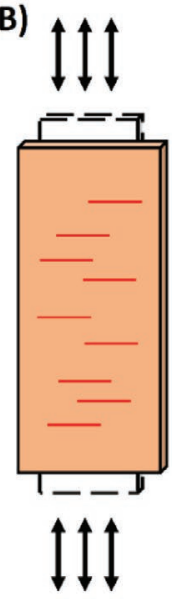

(C)

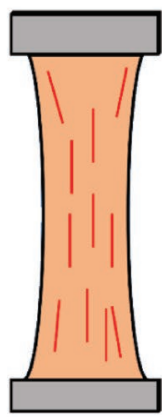

(D)

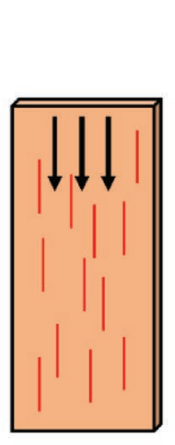

(E)

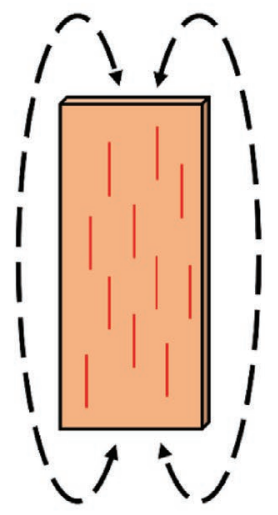

Figure 7. Schematic representation showing different methods of inducing collagen alignment: A) static tensile stretch; B) cyclic tensile stretch; C) tethering at opposite ends to allow contraction by cells; D) shear-induced alignment via flow; E) magnetic field alignment. Arrows represent direction of strain/flow/flux; red lines represent collagen orientation.

could potentially be applied to generate "smart" corneal scaffolds. One of the more promising are gene-activate scaffolds that can transfect cells using viral vectors or nanoparticles. ${ }^{[270]}$ Extensive research has been conducted to use this approach to fabricate scaffold to enhance bone repair, ${ }^{[271]}$ in addition to regenerating other tissues such as cartilage ${ }^{[272]}$ and skin. ${ }^{[273]}$ While the use of gene therapies to treat damaged or diseased corneas has been examined, ${ }^{[274]}$ the use of scaffolds to delivery genes to the cornea remains unexplored. Scaffold designed to inhibit inflammation or infection are also been explored for other tissues. ${ }^{[275]}$ Despite the corneas immune prevalent status, many cornea transplants eventually undergo rejection due to inflammation or neovascularization, ${ }^{[276]}$ therefore there is potential for anti-inflammatory corneal scaffolds to be developed for high-risk patients.

One of the biggest challenges facing researchers is translating their research from the lab to the clinic. In most developed countries, scaffolds need to undergo extensive testing and adhere to rigorous regulatory guidelines prior to use in clinical trials. This is particularly the case for cell-seeded scaffolds. This has led to a recent trend by some researchers to trial their therapies in developing countries where regulations are less strict. While this may speed up the development of new therapies, it does raise ethical concerns. If a therapy is not deemed safe enough to be tested in richer countries, why is it safe to use in poorer countries?

In addition to the clinical translation of corneal scaffolds, their commercial value has to be considered. Due to the high costs associated with developing and manufacturing cell-based therapies, cell free scaffolds for replacing the stroma will appear to be more attractive to produce for companies than cell-seeded scaffolds. Cell free scaffolds also have a longer shelf life and do not require storage under cell culture conditions. For epithelial damage or limbal stem cell deficiencies, cells are required for repair and regeneration. While it is more challenging to get this to market, one example of a cell-based therapy that has successfully undergone regulatory approval and commercialization is Holoclar, a cell-based treatment involving the expansion of limbal derived stem cells in vitro and recently received approval from the European Medicines Agency, to treat limbal deficiency due to burns. ${ }^{[277]}$

In summary, while great progress has been made in developing scaffold for corneal tissue engineering and regeneration, a number of challenges remain in translating current research to the clinic. The success or failure of on-going clinical trials will have a significant impact on the ability of future therapies to treat patients.

\section{Acknowledgements}

The research leading to these results received funding from the European Research Council (ERC) under the European Union's Horizon 2020 Research and Innovation Program (grant agreement no. 637460) and from Science Foundation Ireland (15/ERC/3269).

\section{Conflict of Interest}

The authors declare no conflict of interest.

\section{Keywords}

biomaterials, cornea, hydrogels, scaffolds, tissue engineering

Received: October 30, 2019

Revised: January 8, 2020

Published online:

[1] a) H. S. Dua, V. A. Shanmuganathan, A. O. Powell-Richards, P. J. Tighe, A. Joseph, Brit. J. Ophthalmol. 2005, 89, 529; b) A. M. H. Yeung, U. Schloetzer-Schrehardt, B. Kulkarni, N. L. Tint, A. Hopkinson, H. S. Dua, Arch. Ophthalmol. 2008, 126, 665.

[2] a) J. A. Last, S. J. Liliensiek, P. F. Nealey, C. J. Murphy, J. Struct. Biol. 2009, 167, 19; b) J. A. Last, S. M. Thomasy, C. R. Croasdale, P. Russell, C. J. Murphy, Micron 2012, 43, 1293. 
[3] K. M. Meek, Biophys. Rev. 2009, 1, 83.

[4] E. L. Martola, J. L. Baum, Arch. Ophthalmol. 1968, 79, 28

[5] a) T. B. Abud, A. Di Zazzo, A. Kheirkhah, R. Dana, J. Ophthalmic Vision Res. 2017, 12, 81; b) W. Zhong, M. Montana, S. M. Santosa I. D. Isjwara, Y. H. Huang, K. Y. Han, C. O'Neil, A. Wang, M. S. Cortina, J. de la Cruz, Q. Zhou, M. I. Rosenblatt, J. H. Chang, D. T. Azar, Surv. Ophthalmol. 2018, 63, 453; c) A. W. Taylor, Front. Immunol. 2016, 7, 37

[6] a) V. Romano, M. Dinsdale, S. Kaye, Lancet 2019, 102, 306; b) P. Gain, R. Jullienne, Z. He, M. Aldossary, S. Acquart, F. Cognasse, G. Thuret, JAMA Ophthalmol. 2016, 134, 167; c) A. M. Williams, K. W. Muir, Clin. Ophthalmol. 2018, 12, 1049.

[7] A. Crnej, E. I. Paschalis, B. Salvador-Culla, A. Tauber, B. Drnovsek-Olup, L. Q. Shen, C. H. Dohlman, Cornea 2014, 33, 349.

[8] a) M. Nouri, H. Terada, E. C. Alfonso, C. S. Foster, M. L. Durand, C. H. Dohlman, Arch. Ophthalmol. 2001, 119, 484; b) I. Behlau, K. V. Martin, J. N. Martin, E. N. Naumova, J. J. Cadorette, J. T. Sforza, R. Pineda, C. H. Dohlman, Acta Ophthalmol. 2014, 92, e546.

[9] R. K. Talati, J. A. Hallak, F. I. Karas, J. de la Cruz, M. S. Cortina, Cornea 2018, 37, 145.

[10] S. Bouhout, M. C. Robert, S. Deli, M. Harissi-Dagher, Ocul. Immunol. Inflammation 2018, 26, 693.

[11] a) C. A. Vacanti, J. P. Vacanti, Surg. Technol. Int. 1991, I, 43; b) R. Langer, J. P. Vacanti, Science 1993, 260, 920.

[12] a) S. Matthyssen, B. Van den Bogerd, S. N. Dhubhghaill, C. Koppen, N. Zakaria, Acta Biomater. 2018, 69, 31; b) N. Lagali, Curr. Eye Res. 2019, https://doi.org/10.1080/02713683.2019.16638 741.

[13] V. J. Wicklein, B. B. Singer, T. Scheibel, S. Salehi, in Nanoengineered Biomaterials for Regenerative Medicine (Eds: M. Mozafari, J. Rajadas, D. Kaplan), Elsevier, Amsterdam 2019, Ch. 17, p. 379.

[14] A. Isidan, S. Liu, P. Li, M. Lashmet, L. J. Smith, H. Hara, D. K. C. Cooper, B. Ekser, Xenotransplantation 2019, 26, e12564.

[15] B. Zhang, Q. Xue, J. Li, L. Ma, Y. Yao, H. Ye, Z. Cui, H. Yang, Med. Eng. Phys. 2019, 71, 68.

[16] C. Y. Park, J. K. Lee, P. K. Gore, C. Y. Lim, R. S. Chuck, Ophthalmology 2015, 122, 2432.

[17] a) T. Rock, J. Landenberger, M. Bramkamp, K. U. Bartz-Schmidt, D. Rock, Ann. Transplant. 2017, 22, 749; b) U. de Sanctis, C. Alovisi, L. Bauchiero, G. Caramello, G. Girotto, C. Panico, L. Vinai, F. Genzano, A. Amoroso, F. Grignolo, Int. J. Ophthalmol. 2016, 9, 48; c) D. J. Coster, M. T. Lowe, M. C. Keane, K. A. Williams, Australian Corneal Graft Registry Contributors, Ophthalmology 2014; d) E. Flockerzi, P. Maier, D. Bohringer, H. Reinshagen, F. Kruse, C. Cursiefen, T. Reinhard, G. Geerling, N. Torun, B. Seitz, G. K. R. Contr, Am. J. Ophthalmol. 2018, 188, 91

[18] a) N. C. Joyce, S. E. Navon, S. Roy, J. D. Zieske, Invest. Ophthalmol. Visual Sci. 1996, 37, 1566; b) N. C. Joyce, D. L. Harris, Mol. Vision 2010, 16, 897; c) N. C. Joyce, Prog. Retinal Eye Res. 2003, 22, 359.

[19] J. Liu, H. Sheha, Y. Fu, L. Liang, S. C. Tseng, Expert Rev. Ophthalmol. 2010, 5, 645 .

[20] C. M. Murphy, M. G. Haugh, F. J. O'Brien, Biomaterials 2010, 31, 461.

[21] V. Quaranta, J. Cell Biol. 2000, 149, 1167

[22] a) P. Sharma, C. Ng, A. Jana, A. Padhi, P. Szymanski, J. S. H. Lee, B. Behkam, A. S. Nain, Mol. Biol. Cell 2017, 28, 2579; b) Y. Yang, I. Wimpenny, M. Ahearne, Nanomedicine 2011, 7, 131; c) C. M. Chen, J. C. Tang, Y. Gu, L. L. Liu, X. Z. Liu, L. F. Deng, C. Martins, B. Sarmento, W. G. Cui, L. Chen, Adv. Funct. Mater. 2019, 29, 1970024

[23] a) V. Agrawal, S. A. Johnson, J. Reing, L. Zhang, S. Tottey, G. Wang, K. K. Hirschi, S. Braunhut, L. J. Gudas, S. F. Badylak, Proc. Natl.
Acad. Sci. USA 2010, 107, 3351; b) S. A. DeLong, J. J. Moon, J. L. West, Biomaterials 2005, 26, 3227.

[24] a) J. V. Jester, A. Budge, S. Fisher, J. Y. Huang, Invest. Ophthalmol. Visual Sci. 2005, 46, 2369; b) D. L. Van Horn, D. D. Sendele, S. Seideman, P. J. Buco, Invest. Ophthalmol. Visual Sci. 1977, 16, 597.

[25] a) M. A. Watsky, M. M. Jablonski, H. F. Edelhauser, Curr. Eye Res. 1988, 7, 483; b) B. Jue, D. M. Maurice, J. Biomech. 1986, $19,847$.

[26] a) J. Fernandez-Perez, M. Ahearne, Curr. Eye Res. 2019, 44, 135; b) A. P. Lynch, F. O'sullivan, M. Ahearne, Exp. Eye Res. 2016, 151, 26.

[27] J. D. M. Campbell, S. Ahmad, A. Agrawal, C. Bienek, A. Atkinson, N. W. A. Mcgowan, S. Kaye, S. Mantry, K. Ramaesh, A. Glover, J. Pelly, C. MacRury, M. MacDonald, E. Hargreaves, J. Barry, J. Drain, B. Cuthbertson, L. Nerurkar, I. Downing, A. R. Fraser, M. L. Turner, B. Dhillon, Stem Cells Transl. Med. 2019, 8, 323.

[28] a) S. H. Park, K. W. Kim, Y. S. Chun, J. C. Kim, Exp. Eye Res. 2012, 101, 16; b) H. S. Liu, J. H. Zhang, C. Y. Liu, Y. Hayashi, W. W. Y. Kao, J. Cell. Mol. Med. 2012, 16, 1114.

[29] a) S. Zhang, L. Espandar, K. M. Imhof, B. A. Bunnell, J. Clin. Exp. Ophthalmol. 2013, 4, 11435; b) M. Ahearne, J. Lysaght, A. P. Lynch, Cell Regener. 2014, 3, 3:13; c) Y. Du, D. S. Roh, M. L. Funderburgh, M. M. Mann, K. G. Marra, J. P. Rubin, X. Li, J. L. Funderburgh, Mol. Vision 2010, 16, 2680.

[30] a) A. A. Chan, A. J. Hertsenberg, M. L. Funderburgh, M. M. Mann, Y. Q. Du, K. A. Davoli, J. D. Mich-Basso, L. Yang, J. L. Funderburgh, PLoS One 2013, 8, 56831; b) Q. Zhu, M. M. Li, C. Yan, Q. Q. Lu, S. H. Wei, R. Gao, M. F. Yu, Y. Zou, G. Sriram, H. J. Tong, W. Hunziker, C. J. Seneviratne, Z. Y. Gong, B. R. Olsen, T. Cao, Biotechnol. J. 2017, 12, 1700067.

[31] D. Karamichos, C. B. Rich, A. E. Hutcheon, R. Ren, B. Saitta, V. Trinkaus-Randall, J. D. Zieske, J. Funct. Biomater. 2011, 2, 213.

[32] A. Dos Santos, A. Balayan, M. L. Funderburgh, J. Ngo, J. L. Funderburgh, S. X. Deng, Invest. Ophthalmol. Visual Sci. 2019, 60, 3013.

[33] a) A. I. Caplan, Stem Cells Transl. Med. 2017, 6, 1445; b) T. S. de Windt, L. A. Vonk, D. B. F. Saris, Stem Cells Transl. Med. 2017, 6, 1747 .

[34] K. Chakrabarty, R. Shetty, A. Ghosh, Stem Cell Res. Ther. 2018, 9, 287.

[35] a) C. Couture, K. Zaniolo, P. Carrier, J. Lake, J. Patenaude, L. Germain, S. L. Guérin, Biomaterials 2016, 78, 86; b) S. Proulx, J. d'Arc Uwamaliya, P. Carrier, A. Deschambeault, C. Audet, C. J. Giasson, S. L. Guérin, F. A. Auger, L. Germain, Mol. Vision 2010, 16, 2192; c) D. Karamichos, X. Q. Guo, A. E. Hutcheon, J. D. Zieske, Invest. Ophthalmol. Visual Sci. 2010, 51, 1382; d) R. Ren, A. E. Hutcheon, X. Q. Guo, N. Saeidi, S. A. Melotti, J. W. Ruberti, J. D. Zieske, V. Trinkaus-Randall, Dev. Dyn. 2008, 237, 2705; e) X. Q. Guo, A. E. K. Hutcheon, S. A. Melotti, J. D. Zieske, V. Trinkaus-Randall, J. W. Ruberti, Invest. Ophthalmol. Visual Sci. 2007, 48, 4050; f) T. B. McKay, D. Karamichos, A. E. K. Hutcheon, X. Guo, J. D. Zieske, Bioengineering 2019, 6, 110. g) R. M. Gouveia, V. Castelletto, I. W. Hamley, C. J. Connon, Tissue Eng., Part A 2015, 21, 1772.

[36] a) P. Kumar, A. Pandit, D. Zeugolis, Adv. Mater. 2016, 28, 5381; b) P. Kumar, A. Satyam, X. Fan, Y. Rochev, B. J. Rodriguez, A. Gorelov, L. Joshi, M. Raghunath, A. Pandit, D. I. Zeugolis, Tissue Eng., Part C 2015, 21, 660.

[37] R. M. Gouveia, E. Gonzalez-Andrades, J. C. Cardona, C. Gonzalez-Gallardo, A. M. Ionescu, I. Garzon, M. Alaminos, M. Gonzalez-Andrades, C. J. Connon, Biomaterials 2017, 121, 205.

[38] K. Nishida, M. Yamato, Y. Hayashida, K. Watanabe, N. Maeda, H. Watanabe, K. Yamamoto, S. Nagai, A. Kikuchi, Y. Tano, T. Okano, Transplantation 2004, 77, 379. 
[39] a) S. Molladavoodi, H. J. Kwon, J. Medley, M. Gorbet, Acta Biomater. 2015, 11, 324; b) S. Masterton, M. Ahearne, R. Soc. Open Sci. 2019, 6, 191796.

[40] a) R. R. Jones, I. W. Hamley, C. J. Connon, Stem Cell Res. 2012, 8, 403; b) R. M. Gouveia, G. Lepert, S. Gupta, R. R. Mohan, C. Paterson, C. J. Connon, Nat. Commun. 2019, 10, 1496; c) R. M. Gouveia, F. Vajda, J. A. Wibowo, F. Figueiredo, C. J. Connon, Cells 2019, 8, 347.

[41] a) B. Dreier, S. M. Thomasy, R. Mendonsa, V. K. Raghunathan, P. Russell, C. J. Murphy, Invest. Ophthalmol. Visual Sci. 2013, 54, 5901; b) W. M. Petroll, M. Vishwanath, L. Ma, Invest. Ophthalmol. Visual Sci. 2004, 45, 3466; c) D. Karamichos, N. Lakshman, W. M. Petroll, Invest. Ophthalmol. Visual Sci. 2007, 48, 5030.

[42] R. N. Palchesko, K. L. Lathrop, J. L. Funderburgh, A. W. Feinberg, Sci. Rep. 2015, 5, 7955.

[43] S. M. Thomasy, V. K. Raghunathan, H. Miyagi, A. T. Evashenk, J. C. Sermeno, G. K. Tripp, J. T. Morgan, C. J. Murphy, Exp. Eye Res. 2018, 170, 101.

[44] S. Masterton, M. Ahearne, Exp. Eye Res. 2018, 177, 122.

[45] a) M. Ahearne, Y. Yang, K. Y. Then, K. K. Liu, Ann. Biomed. Eng. 2007, 35, 1608; b) D. H. Glass, C. J. Roberts, A. S. Litsky, P. A. Weber, Invest. Ophthalmol. Visual Sci. 2008, 49, 3919; c) S. Kling, N. Bekesi, C. Dorronsoro, D. Pascual, S. Marcos, PLoS One 2014, 9, e104904.

[46] a) N. Garcia-Porta, P. Fernandes, A. Queiros, J. Salgado-Borges, M. Parafita-Mato, J. M. Gonzalez-Meijome, ISRN Ophthalmol. 2014, 2014, 724546; b) B. J. Blackburn, M. W. Jenkins, A. M. Rollins, W. J. Dupps, Front. Bioeng. Biotechnol. 2019, 7, 66; c) F. Boschetti, V. Triacca, L. Spinelli, A. Pandolfi, J. Biomech. Eng. 2012, 134, 031003.

[47] a) M. L. Borene, V. H. Barocas, A. Hubel, Ann. Biomed. Eng. 2004, 32, 274; b) A. Edwards, M. R. Prausnitz, AIChEJ. 1998, 44, 214.

[48] a) K. Y. Then, Y. Yang, M. Ahearne, A. J. El Haj, Curr. Eye Res. 2011, 36, 88; b) S. Koo, S. J. Ahn, H. Zhang, J. C. Wang, E. K. F. Yim, Cell Mol. Bioeng. 2011, 4, 399; c) A. I. Teixeira, P. F. Nealey, C. J. Murphy, J. Biomed. Mater. Res. 2004, 71A, 369; d) S. J. Liliensiek, S. Campbell, P. F. Nealey, C. J. Murphy, J. Biomed. Mater. Res., Part A 2006, 79A, 185.

[49] G. A. Abrams, S. S. Schaus, S. L. Goodman, P. F. Nealey, C. J. Murphy, Cornea 2000, 19, 57.

[50] a) K. B. Kang, B. D. Lawrence, X. R. Gao, Y. C. Luo, Q. Zhou, A. H. Liu, V. H. Guaiquil, M. I. Rosenblatt, Invest. Ophthalmol. Visual Sci. 2017, 58, 6388; b) A. I. Teixeira, G. A. Abrams, P. J. Bertics, C. J. Murphy, P. F. Nealey, J. Cell Sci. 2003, 116, 1881.

[51] S. L. Wilson, I. Wimpenny, M. Ahearne, S. Rauz, A. J. El Haj, Y. Yang, Adv. Funct. Mater. 2012, 22, 3641.

[52] R. M. Gouveia, E. Koudouna, J. Jester, F. Figueiredo, C. J. Connon, Adv. Biosyst. 2017, 1, 1700135.

[53] M. Ahearne, K. K. Liu, A. J. El Haj, K. Y. Then, S. Rauz, Y. Yang, Tissue Eng., Part C 2010, 16, 319.

[54] K. E. Myrna, S. A. Pot, C. J. Murphy, Vet. Ophthalmol. 2009, 12, 25.

[55] a) J. Mo, S. Neelam, J. Mellon, J. R. Brown, J. Y. Niederkorn, Invest. Ophthalmol. Visual Sci. 2017, 58, 137; b) S. Neelam, J. Mellon, A. Wilkerson, J. Y. Niederkorn, Invest. Ophthalmol. Visual Sci. 2018, 59, 4738.

[56] J. Doutch, A. J. Quantock, V. A. Smith, K. M. Meek, Biophys. J. 2008, 95, 5092.

[57] R. D. Glickman, Eye Contact Lens: Sci. Clin. Pract. 2011, 37, 196.

[58] a) D. M. Maurice, J. Physiol. 1957, 136, 263; b) G. B. Benedek, Appl. Opt. 1971, 10, 459; c) K. M. Meek, C. Knupp, Prog. Retinal Eye Res. 2015, 49, 1.

[59] a) J. V. Jester, Semin. Cell Dev. Biol. 2008, 19, 82; b) J. V. Jester, T. Moller-Pedersen, J. Y. Huang, C. M. Sax, W. T. Kays,
H. D. Cavangh, W. M. Petroll, J. Piatigorsky, J. Cell Sci. 1999, 112, 613.

[60] L. Robert, J. M. Legeais, A. M. Robert, G. Renard, Pathol. Biol. 2001, 49, 353.

[61] X. Duan, H. Sheardown, Biomaterials 2006, 27, 4608.

[62] L. Germain, F. A. Auger, E. Grandbois, R. Guignard, M. Giasson, H. Boisjoly, S. L. Guerin, Pathobiology 1999, 67, 140.

[63] E. J. Orwin, A. Hubel, Tissue Eng. 2000, 6, 307.

[64] a) S. Mi, B. Chen, B. Wright, C. J. Connon, J. Biomed. Mater. Res. Part A 2010, 95A, 447; b) Q. Ke, X. Wang, Q. Gao, Z. Wu, P. Wan, W. Zhan, J. Ge, Z. Wang, J. Tissue Eng. Regener. Med. 2011, 5, 138.

[65] X. Duan, C. McLaughlin, M. Griffith, H. Sheardown, Biomaterials $2007,28,78$

[66] J. J. Chae, W. M. Ambrose, F. A. Espinoza, D. G. Mulreany, S. Ng, T. Takezawa, M. M. Trexler, O. D. Schein, R. S. Chuck, J. H. Elisseeff, Acta Ophthalmol. 2015, 93, e57.

[67] a) S. Dravida, S. Gaddipati, M. Griffith, K. Merrett, S. Lakshmi Madhira, V. S. Sangwan, G. K. Vemuganti, J. Tissue Eng. Regener. Med. 2008, 2, 263; b) M. M. Islam, V. Cepla, C. L. He, J. Edin, T. Rakickas, K. Kobuch, Z. Ruzele, W. B. Jackson, M. Rafat, C. P. Lohmann, R. Valiokas, M. Griffith, Acta Biomater. 2015, 12, 70.

[68] W. G. Liu, C. Deng, C. R. McLaughlin, P. Fagerholm, N. S. Lagali, B. Heyne, J. C. Scaiano, M. A. Watsky, Y. Kato, R. Munger, N. Shinozaki, F. F. Li, M. Griffith, Biomaterials 2009, 30, 1551.

[69] C. Deng, F. Li, J. M. Hackett, S. H. Chaudhry, F. N. Toll, B. Toye, W. Hodge, M. Griffith, Acta Biomater. 2010, 6, 187.

[70] a) M. Koulikovska, M. Rafat, G. Petrovski, Z. Vereb, S. Akhtar, P. Fagerholm, N. Lagali, Tissue Eng., Part A 2015, 21, 1116; b) M. Rafat, M. Xeroudaki, M. Koulikovska, P. Sherrell, F. Groth, P. Fagerholm, N. Lagali, Biomaterials 2016, 83, 142.

[71] N. Builles, H. Janin-Manificat, M. Malbouyres, V. Justin, M. R. Rovere, G. Pellegrini, J. Torbet, D. J. S. Hulmes, C. Burillon, O. Damour, F. Ruggiero, Biomaterials 2010, 31, 8313.

[72] Y. Liu, X. Liu, M. H. Wu, P. H. Ji, H. L. Lv, L. H. Deng, Int. J. Biol. Macromol. 2019, 121, 233.

[73] E. Bentley, C. J. Murphy, F. Li, D. J. Carlsson, M. Griffith, Cornea 2010, 29, 910

[74] N. E. Vrana, N. Builles, V. Justin, J. Bednarz, G. Pellegrini, B. Ferrari, O. Damour, D. J. Hulmes, V. Hasirci, Invest. Ophthalmol. Visual Sci. 2008, 49, 5325.

[75] a) M. Ahearne, S. L. Wilson, K. K. Liu, S. Rauz, A. J. El Haj, Y. Yang, Exp. Eye Res. 2010, 91, 584; b) C. Kilic, A. Girotti, C. Rodriguez-Cabello, V. Hasirci, Biomater. Sci. 2014, 2, 318.

[76] X. Xiao, S. Pan, X. Liu, X. Zhu, C. J. Connon, J. Wu, S. Mi, J. Biomed. Mater. Res., Part A 2014, 102, 1782.

[77] M. Miotto, R. M. Gouveia, A. M. Ionescu, F. Figueiredo, I. W. Hamley, C. J. Connon, Adv. Funct. Mater. 2019, 29, 1807334.

[78] a) E. J. Orwin, M. L. Borene, A. Hubel, J. Biomech. Eng. 2003, 125, 439; b) V. Kishore, R. Iyer, A. Frandsen, T. U. Nguyen, Biomed. Mater. 2016, 11, 055008; c) R. A. Crabb, E. P. Chau, D. M. Decoteau, A. Hubel, Ann. Biomed. Eng. 2006, 34, 1615.

[79] F. Li, M. Griffith, Z. Li, S. Tanodekaew, H. Sheardown, M. Hakim, D. J. Carlsson, Biomaterials 2005, 26, 3093.

[80] C. R. McLaughlin, M. C. Acosta, C. Luna, W. Liu, C. Belmonte, M. Griffith, J. Gallar, Biomaterials 2010, 31, 2770.

[81] a) K. Merrett, P. Fagerholm, C. R. McLaughlin, S. Dravida, N. Lagali, N. Shinozaki, M. A. Watsky, R. Munger, Y. Kato, F. F. Li, C. J. Marmo, M. Griffith, Invest. Ophthalmol. Visual Sci. 2008, 49, 3887; b) N. Lagali, M. Griffith, P. Fagerholm, K. Merrett, M. Huynh, R. Munger, Invest. Ophthalmol. Visual Sci. 2008, 49, 3895.

[82] S. Hayes, P. Lewis, M. M. Islam, J. Doutch, T. Sorensen, T. White, M. Griffith, K. M. Meek, Acta Biomater. 2015, 25, 121. 
[83] a) P. Fagerholm, N. S. Lagali, J. A. Ong, K. Merrett, W. B. Jackson, J. W. Polarek, E. J. Suuronen, Y. Liu, I. Brunette, M. Griffith, Biomaterials 2014, 35, 2420; b) P. Fagerholm, N. S. Lagali, K. Merrett, W. B. Jackson, R. Munger, Y. Liu, J. W. Polarek, M. Soderqvist, M. Griffith, Sci. Transl. Med. 2010, 2, 46ra61; c) P. Fagerholm, N. S. Lagali, D. J. Carlsson, K. Merrett, M. Griffith Clin. Transl. Sci. 2009, 2, 162; d) J. A. Ong, E. Auvinet, K. J. Forget, N. Lagali, P. Fagerholm, M. Griffith, J. Meunier, I. Brunette, Invest. Ophthalmol. Visual Sci. 2016, 57, 2355; e) O. Buznyk N. Pasyechnikova, M. M. Islam, S. Iakymenko, P. Fagerholm, M. Griffith, Clin. Transl. Sci. 2015, 8, 558.

[84] a) Y. J. Cen, Y. Feng, Chin. Med. J. 2018, 131, 1710; b) R. N. Palchesko, J. L. Funderburgh, A. W. Feinberg, Adv. Healthcare Mater. 2016, 5, 2942.

[85] T. Mimura, S. Yamagami, S. Yokoo, T. Usui, K. Tanaka, S. Hattori, S. Irie, K. Miyata, M. Araie, S. Amano, Invest. Ophthalmol. Visual Sci. 2004, 45, 2992.

[86] J. Yoshida, S. Yokoo, A. Oshikata-Miyazaki, S. Amano, T. Takezawa, S. Yamagami, Curr. Eye Res. 2017, 42, 1420.

[87] N. Vazquez, M. Chacon, C. A. Rodriguez-Barrientos, J. Merayo-Lloves, M. Naveiras, B. Baamonde, J. F. Alfonso, I. Zambrano-Andazol, A. C. Riestra, A. Meana, PLoS One 2016, 11, e0167578.

[88] M. Y. Avila, V. A. Gerena, J. L. Navia, Mol. Vision 2012, 18, 1068.

[89] Y. S. Kwon, E. S. Lim, H. M. Kim, Y. C. Hwang, K. W. Lee, K. S. Min, J. Endod. 2015, 41, 501.

[90] M. Ahearne, Y. Yang, K. Y. Then, K. K. Liu, Brit. J. Ophthalmol. 2008, 92, 268.

[91] a) R. A. Brown, M. Wiseman, C. B. Chuo, U. Cheema, S. N. Nazhat, Adv. Funct. Mater. 2005, 15, 1762; b) U. Cheema, R. A. Brown, Adv. Wound Care 2013, 2, 176.

[92] E. E. Antoine, P. P. Vlachos, M. N. Rylander, Tissue Eng., Part B 2014, 20, 683.

[93] E. Davison-Kotler, W. S. Marshall, E. Garcia-Gareta, Bioengineering 2019, 6, 56.

[94] S. L. Wilson, M. Guilbert, J. Sule-Suso, J. Torbet, P. Jeannesson, G. D. Sockalingum, Y. Yang, FASEB J. 2014, 28, 14.

[95] a) J. A. Werkmeister, J. A. Ramshaw, Biomed. Mater. 2012, 7, 012002; b) S. Browne, D. I. Zeugolis, A. Pandit, Tissue Eng., Part A 2013, 19, 1491; c) B. An, D. L. Kaplan, B. Brodsky, Front. Chem. 2014, 2, 40.

[96] L. M. Houdebine, Comp. Immunol., Microbiol. Infect. Dis. 2009, 32, 107.

[97] T. Takezawa, K. Ozaki, A. Nitani, C. Takabayashi, T. Shimo-Oka, Cell Transplant. 2004, 13, 463.

[98] X. Calderon-Colon, Z. Xia, J. L. Breidenich, D. G. Mulreany, Q. Guo, O. M. Uy, J. E. Tiffany, D. E. Freund, R. L. McCally, O. D. Schein, J. H. Elisseeff, M. M. Trexler, Biomaterials 2012, 33, 8286.

[99] a) H. Yamaguchi, T. Takezawa, Drug Metab. Dispos. 2018, 46, 1684; b) H. Yamaguchi, H. Kojima, T. Takezawa, J. Appl. Toxicol. 2016, 36, 1025.

[100] a) T. H. van Essen, L. van Zijl, T. Possemiers, A. A. Mulder, S. J. Zwart, C. H. Chou, C. C. Lin, H. J. Lai, G. P. M. Luyten, M. J. Tassignon, N. Zakaria, A. El Ghalbzouri, M. J. Jager, Biomaterials 2016, 81, 36; b) C. C. Lin, R. Ritch, S. M. Lin, M. H. Ni, Y. C. Chang, Y. L. Lu, H. J. Lai, F. H. Lin, Eur. Cells Mater. 2010, 19, 50.

[101] T. H. van Essen, C. C. Lin, A. K. Hussain, S. Maas, H. J. Lai, H. Linnartz, T. J. T. P. van den Berg, D. C. F. Salvatori, G. P. M. Luyten, M. J. Jager, Invest. Ophthalmol. Visual Sci. 2013, $54,3224$.

[102] F. Yuan, L. Y. Wang, C. C. Lin, C. H. Chou, L. Li, J. Ophthalmol. 2014, 2014, 914542.

[103] S. Krishnan, S. Sekar, M. F. Katheem, S. Krishnakumar, T. P. Sastry, Artif. Organs 2012, 36, 829.

[104] M. Parekh, B. Van den Bogerd, N. Zakaria, D. Ponzin, S. Ferrari, Stem Cells Int. 2018, 2018, 8146834.
[105] a) N. Kasoju, U. Bora, Adv. Healthcare Mater. 2012, 1, 393; b) Y. Wang, J. Guo, L. Zhou, C. Ye, F. G. Omenetto, D. L. Kaplan, S. J. Ling, Adv. Funct. Mater. 2018, 28, 1805305.

[106] a) T. Chirila, Z. Barnard, Zainuddin, D. G. Harkin, I. R. Schwab, L. Hirst, Tissue Eng., Part A 2008, 14, 1203; b) L. J. Bray, K. A. George, S. L. Ainscough, D. W. Hutmacher, T. V. Chirila, D. G. Harkin, Biomaterials 2011, 32, 5086; c) J. Liu, B. D. Lawrence, A. Liu, I. R. Schwab, L. A. Oliveira, M. I. Rosenblatt, Invest. Ophthalmol. Visual Sci. 2012, 53, 4130; d) B. D. Lawrence, Z. Pan, A. Liu, D. L. Kaplan, M. I. Rosenblatt, Acta Biomater. 2012, 8, 3732; e) B. D. Lawrence, Z. Pan, M. I. Rosenblatt, PLoS One 2012, 7, 50190; f) E. Biazar, A. Baradaran-Rafii, S. Heidari-keshel, S. Tavakolifard, J. Biomater. Sci., Polym. Ed. 2015, 26, 1139; g) M. B. Applegate, B. P. Partlow, J. Coburn, B. Marelli, C. Pirie, R. Pineda, D. L. Kaplan, F. G. Omenetto, Adv. Mater. 2016, 28, 2417.

[107] T. A. Hogerheyde, S. Suzuki, S. A. Stephenson, N. A. Richardson, T. V. Chirila, D. G. Harkin, L. J. Bray, Biomed. Mater. 2014, 9, 025016.

[108] L. Jia, C. E. Ghezzi, D. L. Kaplan, J. Biomed. Mater. Res., Part B 2016, 104, 431.

[109] Y. Li, Y. Yang, L. Yang, Y. Zeng, X. Gao, H. Xu, Stem Cell Res. Ther. 2017, 8, 256

[110] a) L. J. Bray, K. A. George, D. W. Hutmacher, T. V. Chirila, D. G. Harkin, Biomaterials 2012, 33, 3529; b) S. Wang, C. E. Ghezzi, R. Gomes, R. E. Pollard, J. L. Funderburgh, D. L. Kaplan, Biomaterials 2017, 112, 1; c) E. A. Gosselin, T. Torregrosa, C. E. Ghezzi, A. C. Mendelsohn, R. Gomes, J. L. Funderburgh, D. L. Kaplan, J. Tissue Eng. Regener. Med. 2018, 12, 285.

[111] S. Hazra, S. Nandi, D. Naskar, R. Guha, S. Chowdhury, N. Pradhan, S. C. Kundu, A. Konar, Sci. Rep. 2016, 6, 21840.

[112] L. Guan, H. Y. Ge, X. L. Tang, S. Su, P. Tian, N. Xiao, H. Zhang, L. Zhang, P. Liu, Cells Tissues Organs 2013, 198, 190.

[113] K. Long, Y. Liu, W. C. Li, L. Wang, S. Liu, Y. J. Wang, Z. C. Wang, L. Ren, J. Biomed. Mater. Res., Part A 2015, 103, 1159.

[114] a) B. D. Lawrence, J. K. Marchant, M. A. Pindrus, F. G. Omenetto, D. L. Kaplan, Biomaterials 2009, 30, 1299; b) E. S. Gil, S. H. Park, J. Marchant, F. Omenetto, D. L. Kaplan, Macromol. Biosci. 2010, 10, 664; c) M. C. Lee, D. K. Kim, O. J. Lee, J. H. Kim, H. W. Ju, J. M. Lee, B. M. Moon, H. J. Park, D. W. Kim, S. H. Kim, C. H. Park, J. Biomed. Mater. Res., Part B 2016, 104, 508; d) W. Zhang, J. L. Chen, L. J. Backman, A. D. Malm, P. Danielson, Adv. Healthcare Mater. 2017, 6, 1601238; e) C. E. Ghezzi, B. Marelli, F. G. Omenetto, J. L. Funderburgh, D. L. Kaplan, PLoS One 2017, 12, 0169504.

[115] C. E. Ghezzi, L. Wang, I. Behlau, J. Rnjak-Kovacina, S. Wang, M. H. Goldstein, J. Liu, J. K. Marchant, M. I. Rosenblatt, D. L. Kaplan, J. Appl. Biomater. Funct. Mater. 2016, 14, 266.

[116] a) E. S. Gil, B. B. Mandal, S. H. Park, J. K. Marchant, F. G. Omenetto, D. L. Kaplan, Biomaterials 2010, 31, 8953; b) J. Wu, J. Rnjak-Kovacina, Y. Du, M. L. Funderburgh, D. L. Kaplan, J. L. Funderburgh, Biomaterials 2014, 35, 3744.

[117] L. N. Guan, P. Tian, H. Y. Ge, X. L. Tang, H. Zhang, L. L. Du, P. Liu, J. Mol. Histol. 2013, 44, 609.

[118] L. Wang, R. Ma, G. Du, H. Guo, Y. Huang, J. Biomed. Mater. Res., Part B 2015, 103, 204.

[119] P. Bhattacharjee, J. Fernandez-Perez, M. Ahearne, Mater. Sci. Eng., C 2019, 105, 110093.

[120] P. W. Madden, J. N. X. Lai, K. A. George, T. Giovenco, D. G. Harkin, T. V. Chirila, Biomaterials 2011, 32, 4076.

[121] N. Vazquez, C. A. Rodriguez-Barrientos, S. D. Aznar-Cervantes, M. Chacon, J. L. Cenis, A. C. Riestra, R. M. Sanchez-Avila, M. Persinal, A. Brea-Pastor, L. F. V. Cueto, A. Meana, J. Merayo-Lloves, Invest. Ophthalmol. Visual Sci. 2017, 58, 3357.

[122] D. K. Kim, B. R. Sim, G. Khang, ACS Appl. Mater. Interfaces 2016, $8,15160$. 
[123] J. Chen, C. Yan, M. Y. Zhu, Q. K. Yao, C. Y. Shao, W. J. Lu, J. Wang, X. M. Mo, P. Gu, Y. Fu, X. Q. Fan, Int. J. Nanomed. 2015, 10, 3337.

[124] E. Y. Kim, N. Tripathy, S. A. Cho, C. K. Joo, D. Lee, G. Khang, Colloids Surf., B 2015, 136, 394.

[125] D. K. Kim, B. R. Sim, J. I. Kim, G. Khang, Colloids Surf., B 2018, $164,340$.

[126] J. E. Song, B. R. Sim, Y. S. Jeon, H. S. Kim, E. Y. Shin, C. Carlomagno, G. Khang, J. Biomater. Sci., Polym. Ed. 2019, 30, 263.

[127] G. H. Darshan, D. Kong, J. Gautrot, S. Vootla, Sci. Rep. 2017, 7, 10344.

[128] K. B. Kang, B. D. Lawrence, X. R. Gao, V. H. Guaiquil, A. Liu, M. I. Rosenblatt, Sci. Rep. 2019, 9, 1507.

[129] C. Y. Jiang, X. Y. Wang, R. Gunawidjaja, Y. H. Lin, M. K. Gupta, D. L. Kaplan, R. R. Naik, V. V. Tsukruk, Adv. Funct. Mater. 2007, 17, 2229.

[130] J. H. Choi, H. Jeon, J. E. Song, J. M. Oliveira, R. L. Reis, G. Khang, Nanomaterials 2018, 8, 290.

[131] P. M. Deardorff, T. B. McKay, S. Wang, C. E. Ghezzi, D. M. Cairns, R. D. Abbott, J. L. Funderburgh, K. R. Kenyon, D. L. Kaplan, Sci. Rep. 2018, 8, 17294.

[132] P. Aramwit, T. Siritientong, T. Srichana, Waste Manage. Res. 2012, 30, 217.

[133] P. Aramwit, S. Kanokpanont, T. Nakpheng, T. Srichana, Int. J. Mol. Sci. 2010, 11, 2200.

[134] T. V. Chirila, S. Suzuki, N. C. McKirdy, Prog. Biomater. 2016, 5, 135.

[135] a) N. Nagai, Y. Fukuoka, M. Ishii, H. Otake, T. Yamamoto, A. Taga, N. Okamoto, Y. Shimomura, Int. J. Mol. Sci. 2018, 19, 1123; b) N. Nagai, T. Murao, Y. Ito, N. Okamoto, M. Sasaki, Biol. Pharm. Bull. 2009, 32, 933.

[136] T. V. Chirila, S. Suzuki, L. J. Bray, N. L. Barnett, D. G. Harkin, Prog. Biomater. 2013, 2, 14.

[137] B. Panilaitis, G. H. Altman, J. Chen, H. J. Jin, V. Karageorgiou, D. L. Kaplan, Biomaterials 2003, 24, 3079.

[138] T. Chlapanidas, S. Farago, G. Lucconi, S. Perteghella, M. Galuzzi, M. Mantelli, M. A. Avanzini, M. C. Tosca, M. Marazzi, D. Vigo, M. L. Torre, M. Faustini, Int. J. Biol. Macromol. 2013, 58, 47.

[139] D. Meller, M. Pauklin, H. Thomasen, H. Westekemper, K.-P. Steuhl, Dtsch. Aerztebl. Int. 2011, 108, 243.

[140] K. Jirsova, G. L. A. Jones, Cell Tissue Banking 2017, 18, 193.

[141] Y. Ishino, Y. Sano, T. Nakamura, C. J. Connon, H. Rigby, N. J. Fullwood, S. Kinoshita, Invest. Ophthalmol. Visual Sci. 2004, 45,800 .

[142] Z. Zhou, D. Long, C. C. Hsu, H. Liu, L. Chen, B. Slavin, H. Lin, X. Li, J. Tang, S. Yiu, S. Tuffaha, H. Q. Mao, Acta Biomater. 2019, 97, 310 .

[143] C. L. Allen, G. Clare, E. A. Stewart, M. J. Branch, O. D. Mclntosh, M. Dadhwal, H. S. Dua, A. Hopkinson, PLoS One 2013, 8, 78441.

[144] W. L. Stoppel, C. E. Ghezzi, S. L. McNamara, L. D. Black 3rd, D. L. Kaplan, Ann. Biomed. Eng. 2015, 43, 657.

[145] Y. Liu, L. Ren, Y. J. Wang, Mater. Sci. Eng., C 2013, 33, 196.

[146] A. de la Mata, T. Nieto-Miguel, M. Lopez-Paniagua, S. Galindo, M. R. Aguilar, L. Garcia-Fernandez, S. Gonzalo, B. Vazquez, J. S. Roman, R. M. Corrales, M. Calonge, J. Mater. Sci.: Mater. Med. 2013, 24, 2819.

[147] W. H. Xu, Z. Y. Wang, Y. Liu, L. P. Wang, Z. W. Jiang, T. Li, W. H. Zhang, Y. Liang, Carbohydr. Polym. 2018, 192, 240.

[148] B. Wright, P. A. De Bank, K. A. Luetchford, F. R. Acosta, C. J. Connon, J. Biomed. Mater. Res., Part A 2014, 102, 3393.

[149] D. Chen, Y. Qu, X. Hua, L. Zhang, Z. Liu, S. C. Pflugfelder, D. Q. Li, Eye 2017, 31, 962.

[150] E. S. Sani, A. Kheirkhah, D. Rana, Z. M. Sun, W. Foulsham, A. Sheikhi, A. Khademhosseini, R. Dana, N. Annabi, Sci. Adv. 2019, 5,1281 .
[151] a) L. Koivusalo, M. Kauppila, S. Samanta, V. S. Parihar, T. Ilmarinen, S. Miettinen, O. P. Oommen, H. Skottman, Biomaterials 2019, 225, 119516; b) L. Koivusalo, J. Karvinen, E. Sorsa, I. Jonkkari, J. Valiaho, P. Kallio, T. Ilmarinen, S. Miettinen, H. Skottman, M. Kellomaki, Mater. Sci. Eng., C 2018, 85, 68.

[152] a) L. Rico-Sanchez, I. Garzon, M. Gonzalez-Andrades, A. Ruiz-Garcia, M. Punzano, A. Lizana-Moreno, J. I. Munoz-Avila, M. C. Sanchez-Quevedo, J. Martinez-Atienza, L. Lopez-Navas, R. Sanchez-Pernaute, R. I. Oruezabal, S. Medialdea, M. D. C. Gonzalez-Gallardo, G. Carmona, S. Sanbonmatsu-Gamez, M. Perez, P. Jimenez, N. Cuende, A. Campos, M. Alaminos, J. Tissue Eng. Regener. Med. 2019, 13, 2142; b) M. Gonzalez-Andrades, R. Mata, M. D. C. Gonzalez-Gallardo, S. Medialdea, S. Arias-Santiago, J. Martinez-Atienza, A. Ruiz-Garcia, L. Perez-Fajardo, A. Lizana-Moreno, I. Garzon, A. Campos, M. Alaminos, G. Carmona, N. Cuende, BMJ Open 2017, 7, 016487.

[153] M. Alaminos, M. Del Carmen Sanchez-Quevedo, J. I. Munoz-Avila, D. Serrano, S. Medialdea, I. Carreras, A. Campos, Invest. Ophthalmol. Visual Sci. 2006, 47, 3311.

[154] a) T. Mimura, S. Amano, S. Yokoo, S. Uchida, S. Yamagami, T. Usui, Y. Kimura, Y. Tabata, Mol. Vision 2008, 14, 1819; b) L.-J. Luo, J.-Y. Lai, S.-F. Chou, Y.-J. Hsueh, D. H.-K. Ma, Acta Biomater. 2018, 65, 123.

[155] a) J. Y. Lai, Y. T. Li, C. H. Cho, T. C. Yu, Int. J. Nanomed. 2012, 7, 1101; b) J. Y. Lai, Int. J. Mol. Sci. 2013, 14, 2036.

[156] H. Goodarzi, K. Jadidi, S. Pourmotabed, E. Sharifi, H. Aghamollaei, Int. J. Biol. Macromol. 2019, 126, 620.

[157] C. K. Bektas, V. Hasirci, J. Tissue Eng. Regener. Med. 2018, 12, 1899.

[158] M. Miron-Mendoza, E. Graham, S. Manohar, W. M. Petroll, Matrix Biol. 2017, 64, 69

[159] K. Tonsomboon, M. L. Oyen, J. Mech. Behav. Biomed. Mater., 2013, 21, 185.

[160] R. Watanabe, R. Hayashi, Y. Kimura, Y. Tanaka, T. Kageyama, S. Hara, Y. Tabata, K. Nishida, Tissue Eng., Part A 2011, 17, 2213

[161] a) J. Y. Lai, D. H. K. Ma, M. H. Lai, Y. T. Li, R. J. Chang, L. M. Chen, PLoS One 2013, 8, 54058; b) J. Y. Lai, P. L. Lu, K. H. Chen, Y. Tabata, G. H. Hsiue, Biomacromolecules 2006, 7, 1836; c) J. Y. Lai, K. H. Chen, G. H. Hsiue, Transplantation 2007, 84, 1222; d) G. H. Hsiue, J. Y. Lai, K. H. Chen, W. M. Hsu, Transplantation 2006, 81, 473.

[162] M. Rizwan, G. S. L. Peh, H. P. Ang, N. C. Lwin, K. Adnan, J. S. Mehta, W. S. Tan, E. K. F. Yim, Biomaterials 2017, 120, 139.

[163] P. L. Lu, J. Y. Lai, D. H. K. Ma, G. H. Hsiue, J. Biomater. Sci., Polym. Ed. 2008, 19, 1.

[164] J. Y. Lai, H. Y. Cheng, D. H. K. Ma, PLoS One 2015, 10, 0136067.

[165] M. C. Echave, L. Saenz del Burgo, J. L. Pedraz, G. Orive, Curr. Pharm. Des. 2017, 23, 3567.

[166] B. J. Rose, S. Pacelli, J. A. Haj, S. H. Dua, A. Hopkinson, J. L. White, R. F. Rose, Materials 2014, 7, 3106.

[167] M. Y. Sun, X. T. Sun, Z. Y. Wang, S. Y. Guo, G. J. Yu, H. Z. Yang, Polymers 2018, 10, 1290.

[168] A. I. Van den Bulcke, B. Bogdanov, N. De Rooze, E. H. Schacht, M. Cornelissen, H. Berghmans, Biomacromolecules 2000, 1, 31.

[169] E. Shirzaei Sani, A. Kheirkhah, D. Rana, Z. Sun, W. Foulsham, A. Sheikhi, A. Khademhosseini, R. Dana, N. Annabi, Sci. Adv. 2019, 5, 1281.

[170] a) M. Ahearne, C. T. Buckley, D. J. Kelly, Biotechnol. Appl. Biochem. 2011, 58, 345; b) M. Ahearne, D. J. Kelly, Biomed. Mater. 2013, 8, 035004.

[171] K. Musselmann, B. Kane, B. Alexandrou, J. R. Hassell, Invest. Ophthalmol. Visual Sci. 2006, 47, 5260.

[172] S. Guhan, S. L. Peng, H. Janbatian, S. Saadeh, S. Greenstein, F. Al Bahrani, A. Fadlallah, T. C. Yeh, S. A. Melki, Brit. J. Ophthalmol. 2018, 102, 1328 
[173] a) N. Nassiri, H. K. Pandya, A. R. Djalilian, Arch. Ophthalmol. 2011, 129, 218; b) B. Sonmez, U. Beden, Cornea 2011, 30, 296; c) J. D. Welder, H. K. Pandya, N. Nassiri, A. R. Djalilian, Ophthalmic Surg., Lasers, Imaging 2012, 43, 323.

[174] A. M. Yeung, L. A. Faraj, O. D. Mclntosh, V. K. Dhillon, H. S. Dua, Eye 2016, 30, 1389.

[175] C. Scalcione, D. Ortiz-Vaquerizas, D. G. Said, H. S. Dua, Eye 2018, 32,463

[176] L. Y. Chen, J. S. Kung, E. E. Manche, Eye Contact Lens: Sci. Clin. Pract. 2018, 44, S210.

[177] a) A. M. Ionescu, M. Alaminos, J. D. Cardona, J.D. G.L. Duran, M. Gonzalez-Andrades, R. Ghinea, A.Campos, E. Hita, M. D. Perez, J. Mech. Behav. Biomed. Mater. 2011, 4, 1963; b) I. Garzon, M. A. Martin-Piedra, C. Alfonso-Rodriguez, M. Gonzalez-Andrades, V. Carriel, C. Martinez-Gomez, A. Campos, M. Alaminos, Invest. Ophthalmol. Visual Sci. 2014, 55, 4073; c) A. M. Ionescu, J. de la Cruz Cardona, M. Gonzalez-Andrades, M. Alaminos, A. Campos, E. Hita, M. del Mar Perez, Cornea 2010, 29,895

[178] a) F. Croisier, C. Jerome, Eur. Polym. J. 2013, 49, 780; b) C.-H. Kim, S. J. Park, D. H. Yang, H. J. Chun, in Novel Biomaterials for Regenerative Medicine (Eds: H. J. Chun, K. Park, C.-H. Kim, G. Khang), Springer, Singapore 2018, p. 475

[179] a) P. Kumar, B. S. Dehiya, A. Sindhu, Int. Nano Lett. 2017, 7, 285; b) T. Freier, H. S. Koh, K. Kazazian, M. S. Shoichet, Biomaterials 2005, 26, 5872

[180] a) K. Y. Lee, D. J. Mooney, Prog. Polym. Sci. 2012, 37, 106; b) M. Szekalska, A. Pucilowska, E. Szymanska, P. Ciosek, K. Winnicka, Int. J. Poly. Sci. 2016, 2016, 7697031

[181] M. Ahearne, Y. Yang, A. J. El Haj, K. Y. Then, K. K. Liu, J. R. Soc. Interface 2005, 2, 455.

[182] a) W. Y. Chen, G. Abatangelo, Wound Repair Regener. 1999, 7, 79; b) K. R. Kirker, Y. Luo, J. H. Nielson, J. Shelby, G. D. Prestwich, Biomaterials 2002, 23, 3661; c) L. A. Solchaga, J. E. Dennis, V. M. Goldberg, A. I. Caplan, J. Orthop. Res. 1999, 17, 205; d) I. L. Kim, R. L. Mauck, J. A. Burdick, Biomaterials 2011, 32, 8771.

[183] M. X. Sun, S. Puri, K. N. Mutoji, Y. M. Coulson-Thomas, V. C. Hascall, D. G. Jackson, T. F. Gesteira, V. J. Coulson-Thomas, Invest. Ophthalmol. Visual Sci. 2019, 60, 1050.

[184] a) Q. Li, H. Wang, Z. Dai, Y. Cao, C. Jin, Cornea 2017, 36, 1343; b) X. C. Lin, Y. N. Hui, Y. S. Wang, H. Meng, Y. J. Zhang, Y. Jin, Vet. Ophthalmol. 2008, 11, 61; c) M. C. Zhang, X. Liu, Y. Jin, D. L. Jiang, X. S. Wei, H. T. Xie, Am. J. Transplant. 2015, 15, 1068; d) Y. Lin, Q. Zheng, S. Hua, Y. Meng, W. Chen, Y. Wang, Sci. Rep. 2017, 7, 9955; e) Z. Wu, Y. Zhou, N. Li, M. Huang, H. Duan, J. Ge, P. Xiang, Z. Wang, Biomaterials 2009, 30, 3513; f) B. Xu, Z. Song, T. Fan, Artif. Organs 2017, 41, 1004.

[185] M. M. Islam, R. Sharifi, S. Mamodaly, R. Islam, D. Nahra, D. B. Abusamra, P. C. Hui, Y. Adibnia, M. Goulamaly, E. I. Paschalis, A. Cruzat, J. Kong, P. H. Nilsson, P. Argueso, T. E. Mollnes, J. Chodosh, C. H. Dohlman, M. Gonzalez-Andrades, Acta Biomater. 2019, 96, 330.

[186] T. J. Keane, R. Londono, N. J. Turner, S. F. Badylak, Biomaterials 2012, 33, 1771

[187] S. Nagata, R. Hanayama, K. Kawane, Cell 2010, 140, 619

[188] a) J. Y. Oh, M. K. Kim, H. J. Lee, J. H. Ko, W. R. Wee, J. H. Lee, Tissue Eng., Part C 2009, 15, 635; b) J. M. Diao, X. Pang, Y. Qiu, Y. Miao, M. M. Yu, T. J. Fan, Exp. Eye Res. 2015, 132, 216; c) S. Proulx, T. Bensaoula, O. Nada, C. Audet, J. d'Arc Uwamaliya, A. Devaux, G. Allaire, L. Germain, I. Brunette, Invest. Ophthalmol. Visual Sci. 2009, 50, 2686

[189] a) S. Sasaki, S. Funamoto, Y. Hashimoto, T. Kimura, T. Honda, S. Hattori, H. Kobayashi, A. Kishida, M. Mochizuki, Mol. Vision 2009, 15, 2022; b) Y. Hashimoto, S. Funamoto, S. Sasaki,
T. Honda, S. Hattori, K. Nam, T. Kimura, M. Mochizuki, T. Fujisato, H. Kobayashi, A. Kishida, Biomaterials 2010, 31, 3941.

[190] a) Y. H. Huang, F. W. Tseng, W. H. Chang, I. C. Peng, D. J. Hsieh, S. W. Wu, M. L. Yeh, Acta Biomater. 2017, 58, 238; b) S. Guler, B. Aslan, P. Hosseinian, H. M. Aydin, Tissue Eng., Part C 2017, 23 , 540.

[191] a) K. Pang, L. Du, X. Wu, Biomaterials 2010, 31, 7257; b) L. Du, X. Wu, Artif. Organs 2011, 35, 691; c) Y. Zhou, Z. Wu, J. Ge, P. Wan, N. Li, P. Xiang, Q. Gao, Z. Wang, Cornea 2011, 30, 73.

[192] a) J. S. Choi, J. K. Williams, M. Greven, K. A. Walter, P. W. Laber, G. Khang, S. Soker, Biomaterials 2010, 31, 6738; b) H. Luo, Y. Lu, T. Wu, M. Zhang, Y. Zhang, Y. Jin, Biomaterials 2013, 34, 6748.

[193] a) W. Shi, Q. Zhou, H. Gao, S. Li, M. Dong, T. Wang, Y. Jia, C. Dong, X. Wang, Z. Guo, L. Zhao, X. Hu, L. Xie, Adv. Funct. Mater. 2019, 29, 1902491; b) M. Dong, L. Zhao, F. Wang, X. Hu, H. Li, T. Liu, Q. Zhou, W. Shi, J. Tissue Eng. 2019, 10 2041731419875876.

[194] S. Ponce Marquez, V. S. Martinez, W. Mclntosh Ambrose, J. Wang, N. G. Gantxegui, O. Schein, J. Elisseeff, Acta Biomater. 2009, 5 , 1839.

[195] H. J. Lin, T. J. Wang, T. W. Li, Y. Y. Chang, M. T. Sheu, Y. Y. Huang, D. Z. Liu, Tissue Eng., Part A 2019, 25, 652.

[196] Z. Zhang, G. Niu, J. S. Choi, M. Giegengack, A. Atala, S. Soker, Biomed. Mater. 2015, 10, 035012.

[197] M. Gonzalez-Andrades, J. de la Cruz Cardona, A. M. Ionescu, A. Campos, M. Del Mar Perez, M. Alaminos, Invest. Ophthalmol. Visual Sci. 2011, 52, 215.

[198] a) Y. G. Xu, Y. S. Xu, C. Huang, Y. Feng, Y. Li, W. Wang, Mol. Vision 2008, 14, 2180; b) M. I. Huh, K. P. Lee, J. Kim, S. Yi, B. U. Park, H. K. Kim, J. Ophthalmol. 2018, 2018, 2590536.

[199] J. Xiao, H. Duan, Z. Liu, Z. Wu, Y. Lan, W. Zhang, C. Li, F. Chen, Q. Zhou, X. Wang, J. Huang, Z. Wang, Biomaterials 2011, 32, 6962.

[200] Y. Shao, J. Tang, Y. Zhou, Y. Qu, H. He, Q. Liu, G. Tan, W. Li, Z. Liu, Am. J. Transl. Res. 2015, 7, 2612.

[201] a) J. L. Alio del Barrio, M. Chiesa, N. Garagorri, N. Garcia-Urquia, J. Fernandez-Delgado, L. Bataille, A. Rodriguez, F. ArnalichMontiel, T. Zarnowski, J. P. Alvarez de Toledo, J. L. Alio, M. P. De Miguel, Exp. Eye Res. 2015, 132, 91; b) A. P. Lynch, S. L. Wilson, M. Ahearne, Tissue Eng., Part C 2016, 22, 561.

[202] a) J. Fernandez-Perez, M. Ahearne, Methods 2019, 171, 86; b) S. L. Wilson, L. E. Sidney, S. E. Dunphy, J. B. Rose, A. Hopkinson, J. Funct. Biomater. 2013, 4, 114.

[203] S. L. Wilson, L. E. Sidney, S. E. Dunphy, H. S. Dua, A. Hopkinson, Curr. Eye Res. 2016, 41, 769.

[204] C. A. Utine, J. H. Tzu, E. K. Akpek, Am. J. Ophthalmol. 2011, 151, 170.

[205] a) G. H. Yam, N. Z. Yusoff, T. W. Goh, M. Setiawan, X. W. Lee, Y. C. Liu, J. S. Mehta, Sci. Rep. 2016, 6, 26339; b) H. Yin, P. Qiu, F. Wu, W. Zhang, W. Teng, Z. Qin, C. Li, J. Zhou, Z. Fang, Q. Tang, Q. Fu, J. Ma, Y. Yang, Sci. Rep. 2016, 6, 33848.

[206] Y. Zeng, J. Yang, K. Huang, Z. Lee, X. Lee, J. Biomech. 2001, 34, 533.

[207] R. Sharifi, Y. Yang, Y. Adibnia, C. H. Dohlman, J. Chodosh, M. Gonzalez-Andrades, Sci. Rep. 2019, 9, 1876.

[208] Z. He, F. Forest, A. Bernard, A. S. Gauthier, R. Montard, M. Peoc'h, C. Jumelle, E. Courrier, C. Perrache, P. Gain, G. Thuret, Invest. Ophthalmol. Visual Sci. 2016, 57, 6639.

[209] a) Y. Fu, X. Fan, P. Chen, C. Shao, W. Lu, Cells Tissues Organs 2010 191, 193; b) J. Zhang, C. W. Zhang, L. Q. Du, X. Y. Wu, Int. J. Ophthalmol. 2016, 9, 1; c) M. A. Shafiq, R. A. Gemeinhart, B. Y. Yue, A. R. Djalilian, Tissue Eng., Part C 2012, 18, 340.

[210] J. L. Alio Del Barrio, M. El Zarif, A. Azaar, N. Makdissy, C. Khalil, W. Harb, I. El Achkar, Z. A. Jawad, M. P. de Miguel, J. L. Alio, Am. J. Ophthalmol. 2018, 186, 47.

[211] Y. Hashimoto, S. Funamoto, S. Sasaki, J. Negishi, T. Honda, S. Hattori, K. Nam, T. Kimura, M. Mochizuki, H. Kobayashi, A. Kishida, PLoS One 2015, 10, 0131989. 
[212] H. Hong, M. I. Huh, S. M. Park, K. P. Lee, H. K. Kim, D. S. Kim, Biofabrication 2018, 10, 045001.

[213] J. Zheng, X. Huang, Y. Zhang, Y. Wang, Q. Qin, L. Lin, X. Jin, C. Lam, J. Zhang, Xenotransplantation 2019, 26, 12509.

[214] M.-R. Rovere, C. Ouilhon, D. Salmon, M. Haftek, O. Damour, C. Auxenfans, Cell Tissue Banking 2019, 20, 49.

[215] D. O. Freytes, J. Martin, S. S. Velankar, A. S. Lee, S. F. Badylak, Biomaterials 2008, 29, 1630.

[216] M. T. Wolf, K. A. Daly, E. P. Brennan-Pierce, S. A. Johnson, C. A. Carruthers, A. D'Amore, S. P. Nagarkar, S. S. Velankar, S. F. Badylak, Biomaterials 2012, 33, 7028.

[217] a) R. Gaetani, S. Aouad, L. L. Demaddalena, H. Straessle, M. Dzieciatkowska, M. Wortham, H. R. Bender, K. V. Nguyen-Ngoc, G. W. Schmid-Schoenbein, S. C. George, C. C. W. Hughes, M. Sander, K. C. Hansen, K. L. Christman, Tissue Eng., Part C 2018, 24, 697; b) S. D. Sackett, D. M. Tremmel, F. Ma, A. K. Feeney, R. M. Maguire, M. E. Brown, Y. Zhou, X. Li, C. O'Brien, L. Li, W. J. Burlingham, J. S. Odorico, Sci. Rep. 2018, 8, 10452.

[218] a) T. D. Johnson, S. Y. Lin, K. L. Christman, Nanotechnology 2011, 22, 494015; b) J. L. Ungerleider, T. D. Johnson, N. Rao, K. L. Christman, Methods 2015, 84, 53.

[219] M. J. Sawkins, W. Bowen, P. Dhadda, H. Markides, L. E. Sidney, A. J. Taylor, F. R. Rose, S. F. Badylak, K. M. Shakesheff, L. J. White, Acta Biomater. 2013, 9, 7865.

[220] S. L. Voytik-Harbin, A. O. Brightman, B. Z. Waisner, J. P. Robinson, C. H. Lamar, Tissue Eng. 1998, 4, 157.

[221] H. Lee, W. Han, H. Kim, D.-H. Ha, J. Jang, B. S. Kim, D.-W. Cho, Biomacromolecules 2017, 18, 1229.

[222] F. Pati, J. Jang, D. H. Ha, S. Won Kim, J. W. Rhie, J. H. Shim, D. H. Kim, D. W. Cho, Nat. Commun. 2014, 5, 3935.

[223] S. Farnebo, C. Y. Woon, T. Schmitt, L. M. Joubert, M. Kim, H. Pham, J. Chang, Tissue Eng., Part A 2014, 20, 1550.

[224] V. Magno, J. Friedrichs, H. M. Weber, M. C. Prewitz, M. V. Tsurkan, C. Werner, Acta Biomater. 2017, 55, 109.

[225] a) H. Kim, M.-N. Park, J. Kim, J. Jang, H.-K. Kim, D.-W. Cho, J. Tissue Eng. 2019, 10, 2041731418823382; b) M. Ahearne, A. P. Lynch, Tissue Eng., Part C 2015, 21, 1059; c) M. Ahearne, A. Coyle, J. Mech. Behav. Biomed. Mater. 2016, 54, 259; d) Y. Lu, Q. K. Yao, B. Feng, C. X. Yan, M. Y. Zhu, J. Z. Chen, W. Fu, Y. Fu, J. Biomater. Tissue Eng. 2015, 5, 951.

[226] J. Fernandez-Perez, M. Ahearne, Sci. Rep. 2019, 9, 14933.

[227] a) L. Edgar, A. Altamimi, M. García Sánchez, R. Tamburrinia, A. Asthana, C. Gazia, G. Orlando, Organogenesis 2018, 14, 172; b) J. LeCheminant, C. Field, J. Wound Care 2012, 21, 476; c) G. J. Kruper, Z. P. Vandegriend, H. S. Lin, G. F. Zuliani, Case Rep. Otolaryngol. 2013, 2013, 917183; d) B. N. Brown, W. L. Chung, A. J. Almarza, M. D. Pavlick, S. N. Reppas, M. W. Ochs, A. J. Russell, S. F. Badylak, J. Oral Maxillofac. Surg. 2012, 70, 2656.

[228] H. Yin, Q. Lu, X. Wang, S. Majumdar, A. S. Jun, W. J. Stark, M. P. Grant, J. H. Elisseeff, Acta Biomater. 2019, 85, 192.

[229] H. Yin, X. Wang, S. Majumdar, J. Sohn, B. J. Kim, W. Stark, J. H. Elisseeff, Bioengineering 2019, 6, 90.

[230] M. Huang, N. Li, Z. Wu, P. Wan, X. Liang, W. Zhang, X. Wang, C. Li, J. Xiao, Q. Zhou, Z. Liu, Z. Wang, Biomaterials 2011, 32, 7812.

[231] M. A. Shafiq, B. Y. Milani, A. R. Djalilian, Int. J. Tissue Eng. 2014, 2014, 754245.

[232] B. Aslan, S. Guler, A. Tevlek, H. M. Aydin, J. Biomed. Mater. Res., Part B 2018, 106, 2157.

[233] Y. C. Liu, E. P. W. Teo, H. P. Ang, X. Y. Seah, N. C. Lwin, G. H. F. Yam, J. S. Mehta, Sci. Rep. 2018, 8, 1831.

[234] S. Amano, N. Shimomura, S. Yokoo, K. Araki-Sasaki, S. Yamagami, Mol. Vision 2008, 14, 878

[235] a) Z. J. Wu, B. Kong, R. Liu, W. Sun, S. L. Mi, Nanomaterials 2018, 8, 124; b) Y. Uchino, S. Shimmura, H. Miyashita, T. Taguchi,
H. Kobayashi, J. Shirnazaki, J. Tanaka, K. Tsubota, J. Biomed. Mater. Res., Part B 2007, 81B, 201

[236] G. K. Tummala, T. Joffre, V. R. Lopes, A. Liszka, O. Buznyk, N. Ferraz, C. Persson, M. Griffith, A. Mihranyan, ACS Biomater. Sci. Eng. 2016, 2, 2072.

[237] M. M. Islam, M. Griffith, K. Merrett, in Methods in Molecular Biology, Vol. 1014 (Eds: B. Wright, C. J. Connon), Humana Press, Totowa, NJ 2013, p. 157.

[238] a) S. V. Murphy, A. Atala, Nat. Biotechnol. 2014, 32, 773; b) D. B. Kolesky, R. L. Truby, A. S. Gladman, T. A. Busbee, K. A. Homan, J. A. Lewis, Adv. Mater. 2014, 26, 3124; c) S. B. Ozler, E. Bakirci, C. Kucukgul, B. Koc, J. Biomed. Mater. Res., Part B 2017, 105, 2530; d) M. Kesti, C. Eberhardt, G. Pagliccia, D. Kenkel, D. Grande, A. Boss, M. Zenobi-Wong, Adv. Funct. Mater. 2015, 25, 7406

[239] a) I. Donderwinkel, J. C. M. van Hest, N. R. Cameron, Polym. Chem. 2017, 8, 4451; b) D. A. Foyt, M. D. A. Norman, T. T. L. Yu, E. Gentleman, Adv. Healthcare Mater. 2018, 7, 1700939; c) S. L. Francis, C. Di Bella, G. G. Wallace, P. F. M. Choong, Front. Surg. 2018, 5, 70.

[240] Z. Wu, X. Su, Y. Xu, B. Kong, W. Sun, S. Mi, Sci. Rep. 2016, 6, 24474.

[241] A. Isaacson, S. Swioklo, C. J. Connon, Exp. Eye Res. 2018, 173, 188.

[242] D. F. D. Campos, M. Rohde, M. Ross, P. Anvari, A. Blaeser, M. Vogt, C. Panfil, G. H. F. Yam, J. S. Mehta, H. Fischer, P. Walter, M. Fuest, J. Biomed. Mater. Res., Part A 2019, 107, 1945.

[243] H. Kim, J. Jang, J. Park, K. P. Lee, S. Lee, D. M. Lee, K. H. Kim, H. K. Kim, D. W. Cho, Biofabrication 2019, 11, 035017;

[244] A. Sorkio, L. Koch, L. Koivusalo, A. Deiwick, S. Miettinen, B. Chichkov, H. Skottman, Biomaterials 2018, 171, 57.

[245] J. Park, K. P. Lee, H. Kim, S. Park, R. E. Wijesinghe, J. Lee, S. Han, S. Lee, P. Kim, D. W. Cho, J. Jang, H. K. Kim, M. Jeon, J. Kim, J. Biophotonics 2019, 12, 201900098.

[246] a) D. H. Reneker, I. Chun, Nanotechnology 1996, 7, 216; b) T. J. Sill, H. A. von Recum, Biomaterials 2008, 29, 1989; c) D. Li, Y. N. Xia, Adv. Mater. 2004, 16, 1151.

[247] J. Fernández-Pérez, K. E. Kador, A. P. Lynch, M. Ahearne, Mater. Sci. Eng., C 2020, 108, 110415.

[248] a) M. Kruse, P. Walter, B. Bauer, S. Rutten, K. Schaefer, N. Plange, T. Gries, S. Jockenhoevel, M. Fuest, Curr. Eye Res. 2018, 43, 1; b) S. Sharma, S. Mohanty, D. Gupta, M. Jassal, A. K. Agrawal, R. Tandon, Mol. Vision 2011, 17, 2898; c) S. Sharma, D. Gupta, S. Mohanty, M. Jassal, A. K. Agrawal, R. Tandon, Invest. Ophthalmol. Visual Sci. 2014, 55, 899; d) P. Deshpande, R. McKean, K. A. Blackwood, R. A. Senior, A. Ogunbanjo, A. J. Ryan, S. MacNeil, Regener. Med. 2010, 5, 395; e) P. Stafiej, F. Kung, D. Thieme, M. Czugala, F. E. Kruse, D. W. Schubert, T. A. Fuchsluger, Mater. Sci. Eng., C 2017, 71, 764; f) I. Ortega, A. J. Ryan, P. Deshpande, S. MacNeil, F. Claeyssens, Acta Biomater. 2013, 9, 5511; g) I. Ortega, F. Sefat, P. Deshpande, T. Paterson, C. Ramachandran, A. J. Ryan, S. MacNeil, F. Claeyssens, J. Visualized Exp. 2014, 91, 51826; h) S. Salehi, M. Czugala, P. Stafiej, M. Fathi, T. Bahners, J. S. Gutmann, B. B. Singer, T. A. Fuchsluger, Acta Biomater. 2017, 50, 370.

[249] C. Ramachandran, V. S. Sangwan, I. Ortega, U. Bhatnagar, S. M. A. Mulla, R. McKean, S. MacNeil, Brit. J. Ophthalmol. 2019, 103, 286 .

[250] a) L. S. Wray, E. J. Orwin, Tissue Eng., Part A 2009, 15, 1463; b) D. Phu, L. S. Wray, R. V. Warren, R. C. Haskell, E. J. Orwin, Tissue Eng., Part A 2011, 17, 799.

[251] a) D. I. Zeugolis, S. T. Khew, E. S. Yew, A. K. Ekaputra, Y. W. Tong, L. Y. Yung, D. W. Hutmacher, C. Sheppard, M. Raghunath, Biomaterials 2008, 29, 2293; b) B. Dong, O. Arnoult, M. E. Smith, G. E. Wnek, Macromol. Rapid Commun. 2009, 30, 539; 
c) A. Elamparithi, A. M. Punnoose, S. Kuruvilla, Artif. Cells, Nanomed., Biotechnol. 2016, 44, 1318.

[252] J. I. Kim, J. Y. Kim, C. H. Park, Sci. Rep. 2018, 8, 3424.

[253] a) C. Zhang, J. H. Wen, J. Yan, Y. B. Kao, Z. Q. Ni, X. J. Cui, H. Y. Wang, RSC Adv. 2015, 5, 12123; b) J. Yan, L. H. Qiang, Y. Gao, X. J. Cui, H. Y. Zhou, S. L. Zhong, Q. Wang, H. Y. Wang, J. Biomed. Mater. Res., Part A 2012, 100A, 527.

[254] T. D. Brown, P. D. Dalton, D. W. Hutmacher, Adv. Mater. 2011, 23, 5651.

[255] a) M. Castilho, D. Feyen, M. Flandes-Iparraguirre, G. Hochleitner, J. Groll, P. A. F. Doevendans, T. Vermonden, K. Ito, J. P. G. Sluijter, J. Malda, Adv. Healthcare Mater. 2017, 6, 1700311; b) B. L. Farrugia, T. D. Brown, Z. Upton, D. W. Hutmacher, P. D. Dalton, T. R. Dargaville, Biofabrication 2013, 5, 025001; c) O. Bas, E. M. De-Juan-Pardo, M. P. Chhaya, F. M. Wunner, J. E. Jeon, T. J. Klein, D. W. Hutmacher, Eur. Polym. J. 2015, 72, 451; d) M. L. Muerza-Cascante, A. Shokoohmand, K. Khosrotehrani, D. Haylock, P. D. Dalton, D. W. Hutmacher, D. Loessner, Acta Biomater. 2017, 52, 145.

[256] K. F. Eichholz, D. A. Hoey, Acta Biomater. 2018, 75, 140

[257] D. F. Holmes, C. J. Gilpin, C. Baldock, U. Ziese, A. J. Koster, K. E. Kadler, Proc. Natl. Acad. Sci. USA 2001, 98, 7307.

[258] E. Hadjipanayi, M. Ananta, M. Binkowski, I. Streeter, Z. Lu, Z. F. Cui, R. A. Brown, V. Mudera, J. Tissue Eng. Regener. Med. 2011, 5, 505.

[259] H. J. Levis, A. K. Kureshi, I. Massie, L. Morgan, A. J. Vernon, J. T. Daniels, J. Funct. Biomater. 2015, 6, 50.

[260] H. J. Levis, G. S. L. Peh, K. P. Toh, R. Poh, A. J. Shortt, R. A. L. Drake, J. S. Mehta, J. T. Daniels, PLoS One 2012, 7, 50993.

[261] H. Hong, H. Kim, S. J. Han, J. Jang, H. K. Kim, D.-W. Cho, D. S. Kim, Mater. Sci. Eng., C 2019, 103, 109837.

[262] B. Kong, W. Sun, G. S. Chen, S. Tang, M. Li, Z. W. Shao, S. L. Mi, Sci. Rep. 2017, 7, 970

[263] a) H. J. Levis, I. Massie, M. A. Dziasko, A. Kaasi, J. T. Daniels, Biomaterials 2013, 34, 8860; b) H. J. Levis, J. Menzel-Severing, R. A. Drake, J. T. Daniels, Curr. Eye Res. 2013, 38, 41.

[264] a) D. Vader, A. Kabla, D. Weitz, L. Mahadevan, PLoS One 2009, 4, 5902; b) K. M. Riching, B. L. Cox, M. R. Salick, C. Pehlke, A. S. Riching, S. M. Ponik, B. R. Bass, W. C. Crone, Y. Jiang, A. M. Weaver, K. W. Eliceiri, P. J. Keely, Biophys. J. 2014, 107, 2546

[265] E. Nam, W. C. Lee, S. Takeuchi, Macromol. Biosci. 2016, 16, 995.

[266] a) N. Wang, J. P. Butler, D. E. Ingber, Science 1993, 260, 1124; b) R. Kaunas, P. Nguyen, S. Usami, S. Chien, Proc. Natl. Acad. Sci. USA 2005, 102, 15895; c) M. Chiquet, L. Gelman, R. Lutz, S. Maier, Biochim. Biophys. Acta, Mol. Cell Res. 2009, 1793, 911.

[267] M. Ahearne, P. O. Bagnaninchi, Y. Yang, A. J. El Haj, J. Tissue Eng. Regener. Med. 2008, 2, 521.

[268] a) C. He, T. Ye, W. Teng, Z. Fang, W. S. Ruan, G. Liu, H. Chen, J. Sun, L. Hui, F. Sheng, D. Pan, C. Yang, Y. Zheng, M. B. Luo, K. Yao, B. Wang, ACS Nano 2019, 13, 1910; b) N. Saeidi, E. A. Sander, R. Zareian, J. W. Ruberti, Acta Biomater. 2011, 7, 2437
[269] a) D. L. Worcester, Proc. Natl. Acad. Sci. USA 1978, 75, 5475; b) J. Torbet, M. C. Ronziere, Biochem. J. 1984, 219, 1057; c) I. Torbet, M. Malbouyres, N. Builles, V. Justin, M. Roulet, O. Damour, A. Oldberg, F. Ruggiero, D. J. Hulmes, Biomaterials 2007, 28, 4268.

[270] R. M. Raftery, E. G. Tierney, C. M. Curtin, S. A. Cryan, F. J. O'Brien, J. Controlled Release 2015, 210, 84.

[271] a) H. Lin, Y. Tang, K. Sun, J. W. Xue, W. F. Yin, B. Wang, R. Tuan, Mol. Ther. 2016, 24, S209; b) E. G. Tierney, G. P. Duffy, A. J. Hibbitts, S. A. Cryan, F. J. O'Brien, J. Controlled Release 2012 , 158, 304; c) A. McMillan, M. K. Nguyen, T. Gonzalez-Fernandez, P. L. Ge, X. H. Yu, W. L. Murphy, D. J. Kelly, E. Alsberg, Biomaterials 2018, 161, 240; d) R. M. Raftery, D. P. Walsh, I. M. Castano, A. Heise, G. P. Duffy, S. A. Cryan, F. J. O'Brien, Adv. Mater. 2016 28, 5447; e) C. M. Curtin, G. M. Cunniffe, F. G. Lyons, K. Bessho, G. R. Dickson, G. P. Duffy, F. J. O'Brien, Adv. Mater. 2012, 24, 749.

[272] H. J. Diao, J. L. Wang, C. Shen, S. H. Xia, T. Guo, L. Dong, C. Y. Zhang, J. N. Chen, J. N. Zhao, J. F. Zhang, Tissue Eng., Part A 2009, 15, 2687.

[273] A. K. Reckhenrich, U. Hopfner, F. Krotz, Z. Y. Zhang, C. Koch, M. Kremer, H. G. Machens, C. Plank, J. T. Egana, Biomaterials 2011, 32, 1996.

[274] a) R. R. Mohan, J. T. Rodier, A. Sharma, Ocul. Surf. 2013, 11, 150; b) J. Torrecilla, A. del Pozo-Rodriguez, M. Vicente-Pascual, M. A. Solinis, A. Rodriguez-Gascon, Exp. Eye Res. 2018, 176, 130; c) S. Gupta, J. T. Rodier, A. Sharma, E. A. Giuliano, P. R. Sinha, N. P. Hesemann, A. Ghosh, R. R. Mohan, PLoS One 2017, 12, 0172928.

[275] a) E. Lih, W. Park, K. W. Park, S. Y. Chun, H. Kim, Y. K. Joung, T. G. Kwon, J. A. Hubbell, D. K. Han, ACS Cent. Sci. 2019, 5, 458; b) A. Zakeri Siavashani, J. Mohammadi, K. Maniura-Weber, B. Senturk, J. Nourmohammadi, B. Sadeghi, L. Huber, M. Rottmar, Biomater. Sci. 2019, 8, 148; c) J. Y. Kim, S. Y. Chun, S. H. Lee, E. Lih, J. Kim, D. H. Kim, Y. S. Ha, J. W. Chung, J. N. Lee, B. S. Kim, H. T. Kim, E. S. Yoo, D. K. Han, T. G. Kwon, B. I. Jang, Tissue Eng. Regener. Med. 2018, 15, 381; d) L. Zhang, Z. Cao, T. Bai, L. Carr, J. R. Ella-Menye, C. Irvin, B. D. Ratner, S. Jiang, Nat. Biotechnol. 2013, 31, 553.

[276] a) D. J. Coster, C. F. Jessup, K. A. Williams, Eye 2009, 23, 1894; b) Y. Qazi, P. Hamrah, J. Clin. Cell Immunol. 2013, 2013, 006; c) D. Hos, M. Matthaei, F. Bock, K. Maruyama, M. Notara, T. Clahsen, Y. Hou, V. N. H. Le, A. C. Salabarria, J. Horstmann, B. O. Bachmann, C. Cursiefen, Prog. Retinal Eye Res. 2019, 73, 100768.

[277] a) G. Pellegrini, D. Ardigo, G. Milazzo, G. Iotti, P. Guatelli, D. Pelosi, M. De Luca, Stem Cells Transl. Med. 2018, 7, 146; b) G. Pellegrini, P. Rama, S. Matuska, A. Lambiase, S. Bonini, A. Pocobelli, R. G. Colabelli, L. Spadea, R. Fasciani, E. Balestrazzi, P. Vinciguerra, P. Rosetta, A. Tortori, M. Nardi, G. Gabbriellini, C. E. Traverso, C. Macaluso, L. Losi, A. Percesepe, B. Venturi, F. Corradini, A. Panaras, A. Di Rocco, P. Guatelli, M. De Luca, Regener. Med. 2013, 8, 553; c) P. Rama, S. Matuska, G. Paganoni, A. Spinelli, M. De Luca, G. Pellegrini, N. Engl. J. Med. 2010, 363, 147. 